\title{
Seismic Strengthening Effects Based on Pseudodynamic Testing of a Reinforced Concrete Building Retrofitted with a Wire-Woven Bulk Kagome Truss Damper
}

\author{
Jae-Sung Hwang and Kang Seok Lee \\ School of Architecture, Chonnam National University, Gwangju 500-757, Republic of Korea \\ Correspondence should be addressed to Kang Seok Lee; kslnist@chonnam.ac.kr
}

Received 21 April 2016; Accepted 27 June 2016

Academic Editor: Vadim V. Silberschmidt

Copyright (C) 2016 J.-S. Hwang and K. S. Lee. This is an open access article distributed under the Creative Commons Attribution License, which permits unrestricted use, distribution, and reproduction in any medium, provided the original work is properly cited.

\begin{abstract}
A passive damper with a wire-woven bulk Kagome truss design was recently developed; its applicability as a passive damper to improve the seismic performance of building systems, including shear hysteresis behavior, energy dissipation capacity, and fatigue, was confirmed by material tests. The Kagome truss, a periodic cellular metal type, is composed of evenly distributed helical wires with a constant pitch and helical radius in six directions. The purpose of this study was to develop a new passive damper system for seismic strengthening of existing reinforced concrete (RC) frames. The proposed external connection methodology uses a wirewoven bulk Kagome truss (i.e., a Kagome damper external connection (KDEC) system), to dissipate earthquake energy using the dynamic interaction among an existing building, a support structure, and the Kagome damper installed between them. Four test specimens were designed and then strengthened with the KDEC system. Cyclic loading and pseudodynamic tests were conducted; lateral load-carrying capacity, deformation, and hysteresis characteristics were investigated, as well as the maximum response strength, response ductility, and earthquake damage degree, and compared to a control sample. Test results revealed that the KDEC system effectively dissipated the earthquake energy, showing considerable resilience under large-scale earthquake conditions.
\end{abstract}

\section{Introduction}

It has been widely recognized that the earthquake load is the most important factor in the structural design of building systems. The correlations between the degree of damage and the seismic resistance mechanism of structures in an earthquake have been investigated theoretically and experimentally in many studies. Calculation procedures for shear forces and dynamic responses based on those research results have been developed and adopted in seismic design codes and standards over recent decades, including ASCE 710 [1], AIJ 2010 [2], ACI 318-14, and ACI 318R-14 [3].

Thus, progress in the art of seismic design has resulted in new buildings with improved prospects of satisfactory behavior during an earthquake. At the same time, innovations in seismic design methodologies have created some doubts as to the adequacy of the seismic behavior of existing buildings, as revealed by recently occurring strong earthquakes, including the 1995 Kobe Earthquake in Japan, the 1999
Chi-Chi Earthquake in Taiwan, the 2008 Sichuan Earthquake in China, the 2010 Chile Earthquake, the 2011 Christchurch Earthquake in New Zealand, the 2012 Great East Japan Earthquake, and the 2013 Lushan Earthquake in China.

Over the last three decades, rehabilitation procedures have been promoted, and many seismic strengthening techniques have been developed to improve the seismic performance of existing buildings. Conventional seismic retrofitting techniques to increase the ultimate strength include infilling new shear walls in existing frames, adding steel braces in existing frames, adding side walls (wing walls) to existing columns, and adding buttresses to the exterior frames of a building. Techniques to improve the deformation capacity of existing structural members include jacketing with steel plates, jacketing with steel bands, and jacketing with welded wire fabric and covering concrete. However, these conventional methods have several disadvantages, such as an increase in mass, the requirement for precise construction, and foundation reinforcement problems. Other 


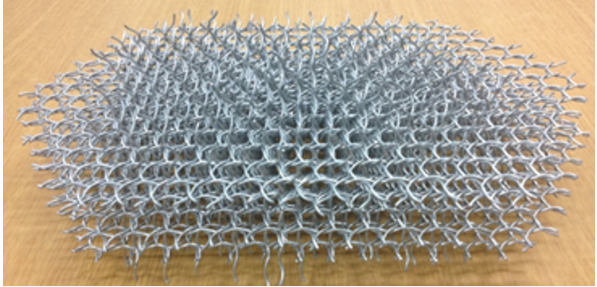

(a)

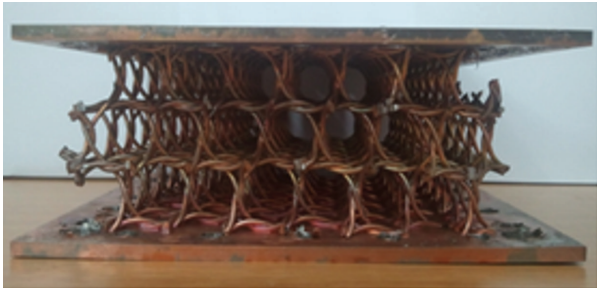

(b)

Figure 1: Configuration of the Kagome truss: (a) wire-woven bulk Kagome fabricated by a three-dimensional assembly of wires and (b) a wire-woven bulk Kagome damper [5].

methods, such as fiber-reinforced polymer (FRP) sheets for seismic strengthening of concrete columns using new lightweight composite materials, such as carbon fiber or glass fiber, have excellent durability and performance and have been applied to overcome the shortcomings of conventional seismic strengthening methods. Nevertheless, the FRPsheet reinforcement method still has drawbacks, such as the requirement for prior surface treatment, problems at joints, fire-resistance problems, and relatively expensive material costs.

Over the past couple of decades, new technologies using vibration control devices have been introduced to strengthen existing structural systems, as well as design new structures to keep a building structure undamaged in an earthquake. These are currently regarded as the most promising earthquake protection systems. Structural design procedures for vibration control devices specified in ASCE 7-10 [1] are classified as damping systems for existing structures and earthquake-resistant systems for seismic design; these are applied separately. Vibration control techniques ensure the seismic safety of the entire structural system, as well as each member, by absorbing the earthquake loads using control devices or members, which have a high energy dissipation capacity, while a conventional structural system could resist earthquake loads via each member element in the structural system.

These devices are classified as passive, active, and semiactive control systems according to the supply system of external energy. Passive control systems have been used widely for seismic strengthening and seismic design of the structures because it is virtually impossible to supply external energy when an earthquake occurs. Passive control devices are categorized into metallic yielding dampers, friction dampers, viscoelastic dampers, and fluid viscous dampers, in accordance with their material properties and energyabsorbing mechanisms [4].

In massive structures such as building systems, the size and capacity of passive control devices should be proportionally large to ensure an enhancement effect of seismic control capacity in terms of a specific level of desired structural performance for the given earthquake demand. Because most installation spaces for control devices inside structures are, however, narrow and limited, a high-performance device must be used rather than simply a large one. Additionally, the passive control devices require miniaturization and weight lightening in limited spaces to enhance the seismic deformation capability, which depends on the intensity of the earthquake ground motion, durability against dynamic fatigue, and age deterioration.

A new passive damper designed using a wire-woven bulk Kagome truss structure, as shown in Figure 1, was developed by Hwang et al. [5]; its applicability as a passive damping material to improve the seismic performance of building systems, including shear hysteresis behavior, energy dissipation capacity, and fatigue, was confirmed based on material tests. The Kagome truss, a periodic cellular metal structure, was first introduced by Wadley et al. [6]. It is composed of helically formed wires with a constant pitch and helical radius in six directions, evenly distributed in space. The Kagome truss is known to have equivalent or even higher strength than an octet truss of the same material and density. Recently, Lee et al. [7] developed a practical fabrication process for the wire-woven bulk Kagome, fabricated using a three-dimensional assembly of wires for mass production.

The main purpose of this study was to develop a new passive damper system for seismic strengthening of existing reinforced concrete (RC) framing systems. The proposed technique is an external connection methodology that uses a wire-woven bulk Kagome truss (referred to as a Kagome damper external connection system or KDEC system). Figure 2 shows a conceptual illustration of the KDEC system proposed here, which consists of an existing building structure, a Kagome damper, and support structure. The KDEC system dissipates the earthquake energy using the dynamic interaction among the existing building structure, the support structure, and the Kagome damper installed between them. Thus, optimal structural properties of the supporting structures and damper, in connection with the existing building structure, are required for effective earthquake energy absorption.

An existing RC frame building, designed by the Korea Land \& Housing Corporation [8], was selected to assess the seismic strengthening effect of the KDEC system proposed here. This study, first, involved preliminary dynamic analyses of the KDEC system, assessing the Kagome damper size, height of support, and ratio of the elastic modulus between the support and existing RC structure as analysis variables to determine the optimum structural properties of the support and damper for the KDEC system. Test specimens strengthened with the KDEC system were designed and fabricated on 


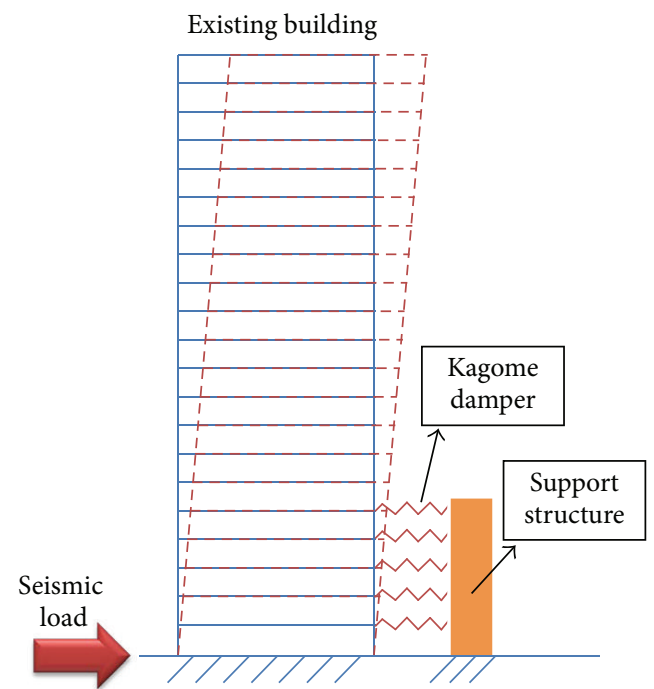

FIGURE 2: Concept of the external connection methodology using a wire-woven bulk Kagome truss.

the basis of the optimum properties derived from the results of the preliminary analyses.

A pseudodynamic test was carried out to verify the seismic strengthening effects of the proposed KDEC system; the test results were compared to the original control RC frame, in terms of maximum response strength, response ductility, and earthquake damage degree under a level of earthquake specified by the seismic design code in Korea [9]. Before the pseudodynamic test, a cyclic loading test was also carried out to estimate the ultimate and yield shear load-carrying capacity and deformation, as well as the hysteresis in the lateral load-drift relationships of the RC frame strengthened with the KDEC system, together with a nonstrengthened frame. The hysteresis properties are needed to determine the test variables for the pseudodynamic test. Four test specimens were designed and fabricated: two for the pseudodynamic test and two for the cyclic loading test.

\section{Preliminary Dynamic Analyses of the KDEC System}

2.1. Overview and Assumptions in the Analysis. The KDEC system used to strengthen the existing RC frame building, designed by the Korea Land \& Housing Corporation [8], consists of the existing building structure, the Kagome damper, and a support structure (Figure 2); the seismic performance of the system depends on the dynamic interaction among them based on their structural properties. As previously stated, the Kagome truss damper is a control device that absorbs earthquake energy by relative displacement at both ends [5-7]. Thus, the relative displacement between the existing RC building and the support structure must be large to effectively dissipate the energy; additionally, the optimal structural properties (i.e., stiffness, height, and size) of the support and Kagome damper should be determined to ensure large displacement.

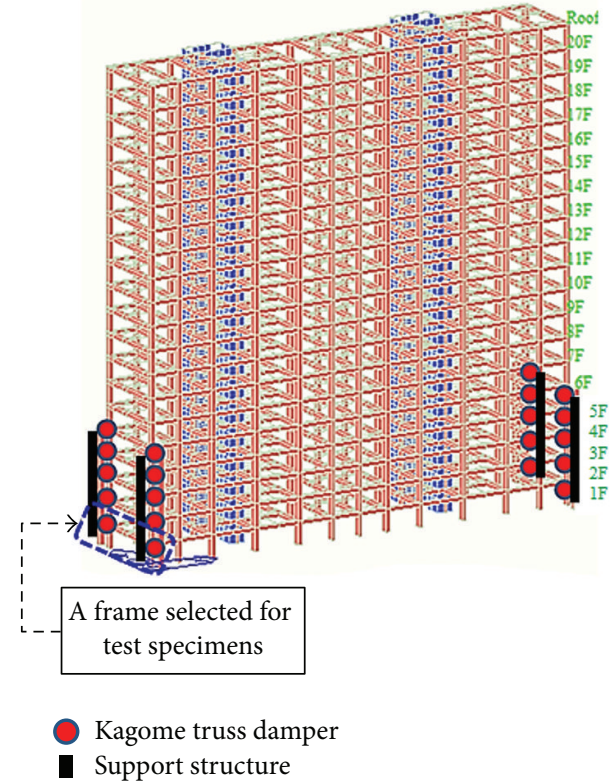

FIGURE 3: The considered existing reinforced concrete (RC) building and installation positions of the support and damper.

In a preliminary analysis, the stiffness and height of the support structure and the size of Kagome damper were set as variables and the boundary nonlinear dynamic analysis technique was used to determine the optimal properties. A boundary analysis assumes that the investigated frame building and support structure behave as linear bodies, and the nonlinearity of the control device is considered [12]. The minimum stiffness ratio and capacity of the support and damper derived from the preliminary analyses were used to design the structural test specimens strengthened using the KDEC system.

Figure 3 shows an isometric perspective of the existing RC frame building considered in this study. The frame building, designed by the Korea Land \& Housing Corporation [8], is a 20 -story RC frame building located in Seoul; the building has a response modification factor of $R=5$. The cross sections of the columns in the building are all $500 \times 800 \mathrm{~mm}$, and the story heights are all $3100 \mathrm{~mm}$. For the analysis, the heights of the support structures were set as three- and five-storyscaled structures with the same story height $(3100 \mathrm{~mm})$ as the original frame building, and their stiffness was selected from multiples in terms of the ratio of the elastic modulus of the original column to that of the support; the ratios used were as follows: $1: 1,1: 3,1: 5,1: 10,1: 50$, and $1: 100$. The material properties of the Kagome truss damper installed between the existing building and support are listed in Table 1. The restoring force $F(t)$ of the damper is based on the Bouc-Wen hysteresis model [13], expressed in the following equations:

$$
F(t)=r K u(t)+(1-r) F_{y} z(t),
$$

where $r$ is the ratio of the postyield stiffness to preyield stiffness $K\left(=F_{y} / u_{y}\right), F_{y}$ is the yield force, $u_{y}$ is the yield 
TABLE 1: Material properties of the Kagome truss damper.

\begin{tabular}{lccccc}
\hline Material properties & $\begin{array}{c}\text { Height } \\
(\mathrm{mm})\end{array}$ & $\begin{array}{c}\text { Yielding } \\
\text { strain }(\%)\end{array}$ & Ultimate strain (\%) & Yielding stress (MPa) & Ultimate stress (MPa) \\
\hline Values & 200 & 0.23 & 15 & 0.79 & 1.31 \\
\hline
\end{tabular}

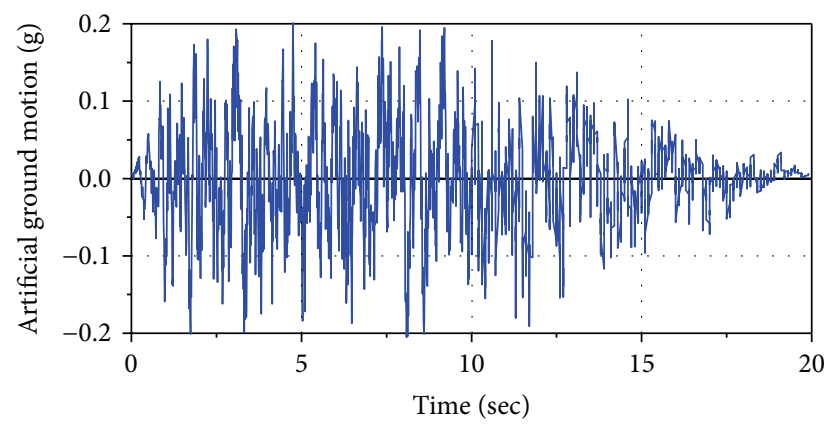

FIGURE 4: Artificial ground motions used in the boundary nonlinear analysis.

displacement, and $z(t)$ is a nonobservable dimensionless hysteresis variable that obeys the following nonlinear differential equation with zero initial condition $(z(0)=0)$ :

$$
\dot{z}(t)=\frac{K}{F_{y}}\left\{1-|z(t)|^{n} \alpha \cdot \operatorname{sign}(\dot{u}(t) z(t))+\beta\right\} \dot{u}(t),
$$

where the coefficient $n$ is the yielding exponent that controls the behavior of the model and $\operatorname{sign}(\cdot)$ is the signum function. $\alpha, \alpha>0$, is a dimensionless quantity controlling the energy dissipation effect, $\beta$ is also a dimensionless parameter representing the shape of nonlinear stiffness of hysteresis loop, and $|\alpha|+|\beta|=1$.

By multiplying the material properties shown in Table 1 by the size of the damper, set as a variable, the yielding and ultimate strengths and deformations can be calculated readily. The cross sections (size) of the dampers used in the analysis ranged from $100 \times 100$ to $800 \times 800 \mathrm{~mm}$ (eight types).

The support structures were installed at the four edges of the building plane, as illustrated in Figure 3, in which the number of dampers is dependent on the height (story) of the support. Figure 3 shows an example of a five-story support structure having in total 20 dampers. Additionally, the artificial ground motions shown in Figure 4 were used as the ground motion acceleration for the boundary nonlinear analysis, generated by the methodology specified in the seismic design code in Korea [9], based on a seismic factor of Zone-1 and condition of Sd soil. In total, 97 analysis cases were carried out to calculate the base shear strength and displacement at the top level of the frame building: there were two support heights, eight damper sizes, and six elastic modulus ratios, including an existing frame building as a control.

2.2. Results of the Analysis. The results of the preliminary analysis, conducted to identify the optimum structural properties for the KDEC system for seismic strengthening, indicated that the reduction effect in terms of the response base shear force, compared with the original building as a control, increased in proportion to the higher stiffness of the support and larger cross-sectional area of the Kagome damper. The presumption is that, due to the higher stiffness of the support, the displacement of the support becomes smaller, resulting in larger relative displacement between the investigated existing building and the support. The Kagome damper is capable of absorbing the earthquake energy using a low range of displacement due to its mechanical characteristics [5]. Thus, if the cross-sectional area of the damper is large, the energy dissipation capability increases proportionally, resulting in a greater reduction in the response base shear force.

Considering the limitations of the support's stiffness and the damper's size and from the relationship regarding the response reduction between them, in the KDEC system, the ratio of the elastic modulus of EM $=1: 10$ between the original column and the support is the most practical result (Table 2). In the table, the shear force ratio is defined as the maximum response base shear force of the building strengthened using the KDEC system divided by that of the control building without the KDEC system. In the case of the support, scaled using a three-story structure having $\mathrm{EM}=1: 10$, the cross sections (size) of the damper of $700 \times 700 \mathrm{~mm}$ and $800 \times$ $800 \mathrm{~mm}$ showed reductions of $\sim 20 \%$ in the base shear force. For the cross sections (size) of the damper of $400 \times 400 \mathrm{~mm}$ through $800 \times 800 \mathrm{~mm}$, the base shear force decreased by $\sim 18 \%$ in the case of a five-story-scaled support having EM = $1: 10$.

The larger size of the damper shows the smaller relative displacement between the structure and the support, as previously stated. This results in a reduction of the energy dissipation of the damper. On the other hand, the smaller sized damper has a limitation in energy dissipation by itself. By the trade-off, the best size of damper should be determined. A smaller damper cross section is advantageous from a practical point of view if the reduction effect on base shear force is similar. As a result, a support scaled using a five-story structure having $E M=1: 10$ and a damper of cross section $400 \times 400 \mathrm{~mm}$ is the "best" result for strengthening the existing $\mathrm{RC}$ frame using the KDEC system proposed in this study.

\section{Structure Tests}

3.1. Specimen Design, Fabrication, and Variables. As previously stated, the building considered in this study is a 20story RC frame structural system located in Seoul, designed according to the seismic design code in Korea [9] using a response modification factor of $R=5$ and the soil condition of Sd. The cross-sectional areas of the columns are all $500 \times 800 \mathrm{~mm}$, and the story height is $3100 \mathrm{~mm}$. For 
TABLE 2: Results of the preliminary analysis and the reduction effect of base shear force by the KDEC system.

\begin{tabular}{|c|c|c|c|c|c|c|}
\hline \multirow{2}{*}{$\begin{array}{l}\text { Support } \\
\text { structure }\end{array}$} & \multirow{2}{*}{$\begin{array}{l}\text { Ratio of elastic } \\
\text { modulus (EM) }\end{array}$} & \multirow{2}{*}{$\begin{array}{c}\text { Damper size } \\
\left(\mathrm{mm}^{2}\right)\end{array}$} & \multirow{2}{*}{$\begin{array}{l}\text { Maximum response } \\
\text { displacement at the } \\
\text { top level of the } \\
\text { building }(\mathrm{mm})\end{array}$} & \multicolumn{2}{|c|}{$\begin{array}{l}\text { Maximum } \\
\text { response base } \\
\text { shear force }\end{array}$} & \multirow{2}{*}{$\begin{array}{c}\text { Maximum } \\
\text { response } \\
\text { displacement of } \\
\text { damper }(\mathrm{mm})\end{array}$} \\
\hline & & & & $\begin{array}{l}\text { Shear } \\
\text { force } \\
(\mathrm{kN})\end{array}$ & $\begin{array}{l}\text { Shear } \\
\text { force } \\
\text { ratio*2 } \\
(\%)\end{array}$ & \\
\hline- & Control $^{* 1}$ & - & 429.1 & 18790 & - & - \\
\hline \multirow{8}{*}{$3 \mathrm{~F}$} & \multirow{8}{*}{10} & $100 \times 100$ & 428.6 & 18666.2 & 0.7 & 28.57 \\
\hline & & $200 \times 200$ & 427.3 & 18323.4 & 2.5 & 26.64 \\
\hline & & $300 \times 300$ & 425.1 & 18163.2 & 3.3 & 24.67 \\
\hline & & $400 \times 400$ & 421.6 & 17171.2 & 8.6 & 22.24 \\
\hline & & $500 \times 500$ & 416.6 & 16532.2 & 12.0 & 19.83 \\
\hline & & $600 \times 600$ & 410.8 & 15762.4 & 16.1 & 17.53 \\
\hline & & $700 \times 700$ & 405.1 & 15058.6 & 19.9 & 15.43 \\
\hline & & $800 \times 800$ & 400.0 & 14725.6 & 21.6 & 13.59 \\
\hline \multirow{8}{*}{$5 \mathrm{~F}$} & \multirow{8}{*}{10} & $100 \times 100$ & 425.9 & 17185.8 & 8.5 & 62.69 \\
\hline & & $200 \times 200$ & 417.8 & 16569.6 & 11.8 & 49.21 \\
\hline & & $300 \times 300$ & 406.9 & 15945.4 & 15.1 & 36.41 \\
\hline & & $400 \times 400$ & 397.6 & 15519.8 & 17.4 & 26.87 \\
\hline & & $500 \times 500$ & 390.8 & 15321.8 & 18.5 & 20.32 \\
\hline & & $600 \times 600$ & 385.8 & 15270.0 & 18.7 & 15.80 \\
\hline & & $700 \times 700$ & 382.1 & 15290.4 & 18.6 & 12.63 \\
\hline & & $800 \times 800$ & 379.6 & 15360.8 & 18.3 & 10.33 \\
\hline
\end{tabular}

${ }^{* 1}$ Control shows the control building without the damper.

${ }^{* 2}$ The shear force ratio is defined as the maximum response base shear force of the building strengthened using the KDEC system divided by that of the control building without the KDEC system, which indicates the reduction effect in terms of the response base shear force compared with the control building.

structural tests (i.e., cyclic loading and pseudodynamic tests), the first story of an external frame (Figure 3) was selected. Table 3 represents comparisons of the dimensions between the existing original frame and the scaled-down specimen for structural tests. The ratio of the dimension reduction is $\sim 50 \%$ (Table 3 ), when the size of the structural laboratory facility, actuator equipment, and the capacity of the overhead travelling crane were considered. The configuration of the scaled-down specimens, including the column and the wall support, was designed and fabricated based on the results of the preliminary analyses in Section 2.2: the support structure (wall) was scaled using a five-story structure having EM = $1: 10$, and the cross section of the damper was $400 \times 400 \mathrm{~mm}$, the "best" result for strengthening the existing RC frame using the KDEC system.

Figures 5 and 6 show the configurations and details of the scaled-down specimens and the Kagome damper for the structural tests, respectively. The purpose of these tests was to verify the seismic strengthening effects, that is, the maximum response strength, response ductility, and earthquake damage degree, as well as hysteresis in the lateral load-drift relationship of the specimen strengthened with the KDEC system, compared to the control specimen. The column specimens and the wall supports were designed according to the guidelines for load-carrying capacity specified by the Japan Building Disaster Prevention Association (JBDPA) [14].
Table 4 gives the specific details of each specimen tested. In total, four test specimens were prepared. They consisted of a control test specimen (nonstrengthened, CL-F) and a test specimen strengthened with the KDEC system (CL-FK) for the cyclic loading test, as well as a control test specimen (nonstrengthened, PD-F) and a test specimen strengthened with the KDEC system (PD-FK) for the pseudodynamic test. All specimens had identical dimensions and rebar arrangements. The cross section of the columns was $250 \times 400 \mathrm{~mm}$, and the ratio of column clear height to depth $\left(\mathrm{h}_{\mathrm{o}} / D\right)$ was 3.13 . The wall supports had a thickness of $25 \mathrm{~mm}$ and a length of $110 \mathrm{~mm}$, and the Kagome damper had a cross-sectional area of $33,000 \mathrm{~mm}^{2}(150 \times 220 \mathrm{~mm})$. Each column was prepared with a 10-D16-type SD400 main rebar, reinforced with shear reinforcement D10 steel bars at $100 \mathrm{~mm}$ intervals. The wall support was used with D19-type SD400 for vertical rebar and D10-type SD400 for horizontal rebar. A stub, with high stiffness, was installed at the top of each specimen to provide confinement of the columns. The average vertical load on each column was $210 \mathrm{kN}$, which is $10 \%$ of the nominal compressive strength of the concrete.

The ground motion acceleration for the pseudodynamic test was the north-south (NS) ground motion recorded at El Centro, as shown in Table 4 . The ground motion was recorded during the 1940 Imperial Valley earthquake, which has been widely used to verify the seismic performance of various building systems. The magnitude of the ground motion was 
TABLE 3: Comparison of dimensions between the existing original frame and scaled-down specimen for structural tests.

\begin{tabular}{lcc}
\hline Object of comparison & Original frame & Dimensions (mm) \\
& $500 \times 800$ & Specimen (scale is 50\% down) \\
\hline Cross section of columns & 3,000 & $250 \times 400$ \\
Height of columns & 500 & 1,500 \\
Thickness of walls (support) & 2,200 & 250 \\
Length of walls (support) & 10,000 & 1,100 \\
Span & $400 \times 400$ & 1,500 \\
Cross section of Kagome damper & 200 & $150 \times 220$ \\
Height of Kagome damper & & 200 \\
\hline
\end{tabular}

TABLE 4: Summary of the test conditions for the cyclic loading and pseudodynamic tests.

\begin{tabular}{lcccc}
\hline Specimens & Test methods & Strengthening types & Clear span of columns (mm) & $\begin{array}{c}\text { Earthquake levels for } \\
\text { pseudodynamic test (gal) }\end{array}$ \\
\hline CL-F & Cyclic loading & - & 1250 & - \\
CL-FK & Cyclic loading & Kagome damper & 1250 & - \\
PD-F & Pseudodynamic & - & 1250 & El Centro (NS): 200, 300 \\
PD-FK & Pseudodynamic & Kagome damper & 1250 & El Centro (NS): 200, 300 \\
\hline
\end{tabular}

CL-F: nonstrengthened control specimen for the cyclic loading test; CL-FK: specimen strengthened with the KDEC system for the cyclic loading test; PD-F: nonstrengthened control specimen for the pseudodynamic test; PD-FK: specimen strengthened with the KDEC system for the pseudodynamic test.

normalized to acceleration values of 200 gal and 300 gal; the ground motion acceleration of 200 gal corresponds to the seismic design load in Zone-1 with the Sd-soil conditions, which shows a two-thirds level of the earthquake ground motion having $2 \%$ probability of exceedance in 50 years (2,500-year return period), as specified in the seismic design code in Korea [9]. A ground motion of 300 gal was additionally set to compare the seismic strengthening effect of the KDEC system in a very strong earthquake; this represents the maximum considered earthquake ground motion with $2 \%$ probability of exceedance in 50 years.

3.2. Material Properties. The listed compressive strength of the concrete was $f_{c}=21 \mathrm{MPa}$; cylindrical compression tests resulted in a figure of $21.7 \pm 1.1 \mathrm{MPa}$. The tensile strength of the steel reinforcing bar (rebar) was $400 \mathrm{MPa}$. Two rebar diameters were used: D10 for shear reinforcement and D16 for the main rebar of the specimens (see Section 3.1 for further details). The wall support used D19 for vertical rebar and D10 for horizontal rebar. The uniform building code [15] pertains to RC design in earthquake zones and specifies that the ratio of the tensile stress to the yield stress of the rebar should not be less than 1.25 , to ensure adequate ductility under simulated earthquake loading. In our tensile testing of the rebar, this ratio was 1.45 for the D10 rebar and 1.35 for the D16 rebar. The tensile strength of the steel rebar was measured using a universal testing machine (UTM); we obtained $472.0 \pm$ 1.31 MPa for D10 rebar, 518.0 $\pm 1.87 \mathrm{MPa}$ for D16 rebar, and $522.1 \pm 2.27 \mathrm{MPa}$ for D19 rebar; the error margins correspond to the standard deviation of the measurement results.

\section{Pseudodynamic Testing Procedures}

4.1. Outline of Pseudodynamic Testing. The most realistic methodology to evaluate the nonlinear response characteristics of a test structure, for example, a building subjected to earthquake ground motions, would be a full-scale structural test on a shaking table. Generally, this is not possible with current experimental facilities, nor will it ever be practical for most large structures. Several alternative approaches have been developed, in which shaking table tests of reducedscale structural models can be used. The drawbacks of such reduced-scale tests are obvious; it is sufficient to point out that many structures cannot be adequately represented by reduced-scale structural models.

The pseudodynamic test method has been developed to carry out realistic experimental tests on full-scale structures subjected to earthquake ground motions [16]. The pseudodynamic test method uses an online computer and associated test instrumentation to monitor and control the structure so that the structural displacement closely resembles what would occur if the structure was subjected to a seismic excitation. The procedure is a self-determined experimental technique. The method is as realistic as shake-table testing, where discretization of the model is feasible. Furthermore, it provides various advantages over shake tables, such as (a) versatility, because it allows for detailed observation of the specimen during the test, (b) the possibility of testing full- and large-scale models, thus eliminating the problems involved with dynamic similitude, (c) no need for actual masses to be provided because the method uses a numerical model, (d) much lower equipment, installation, and operation costs, (e) elimination of problems arising from shake-table interaction with heavy specimens, (f) the fact that physical limitations of the instrumentation make it necessary to carry out the test on a step-by-step basis (i.e., pseudodynamically) although, in principle, the test could be carried out in real time, and (g) improved actuator control and data acquisition reliability due to the relatively slow 


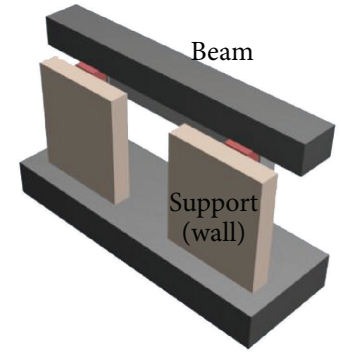

(a)

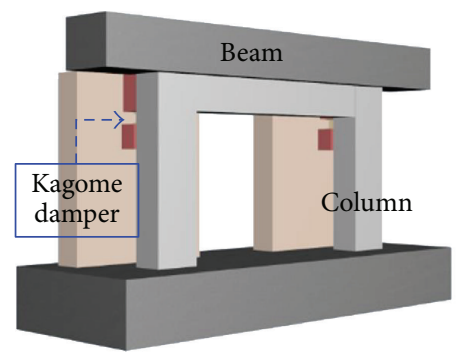

(b)

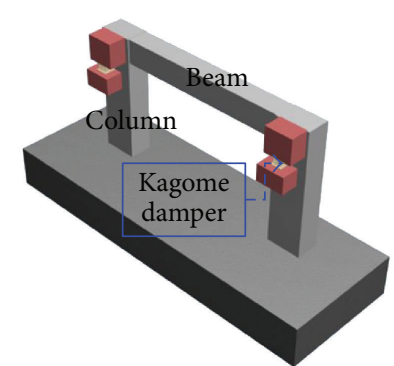

(c)

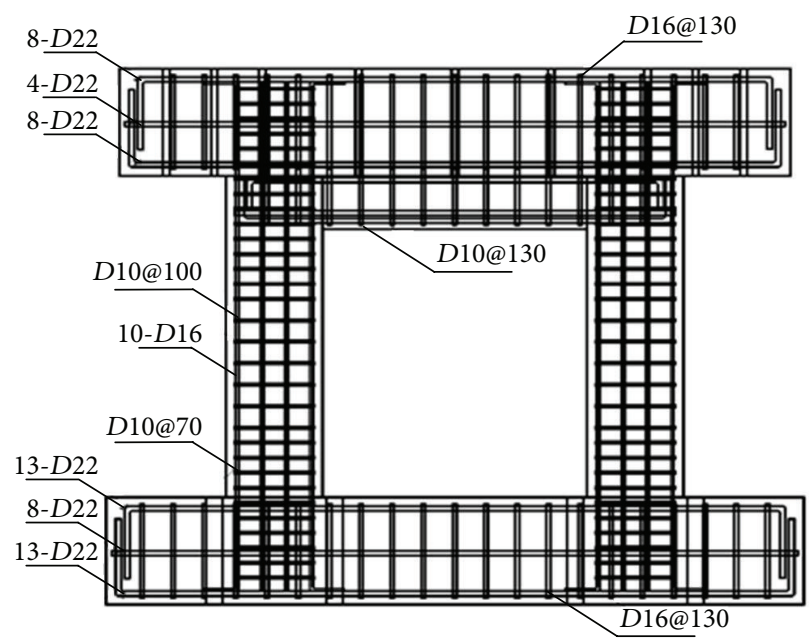

(d)
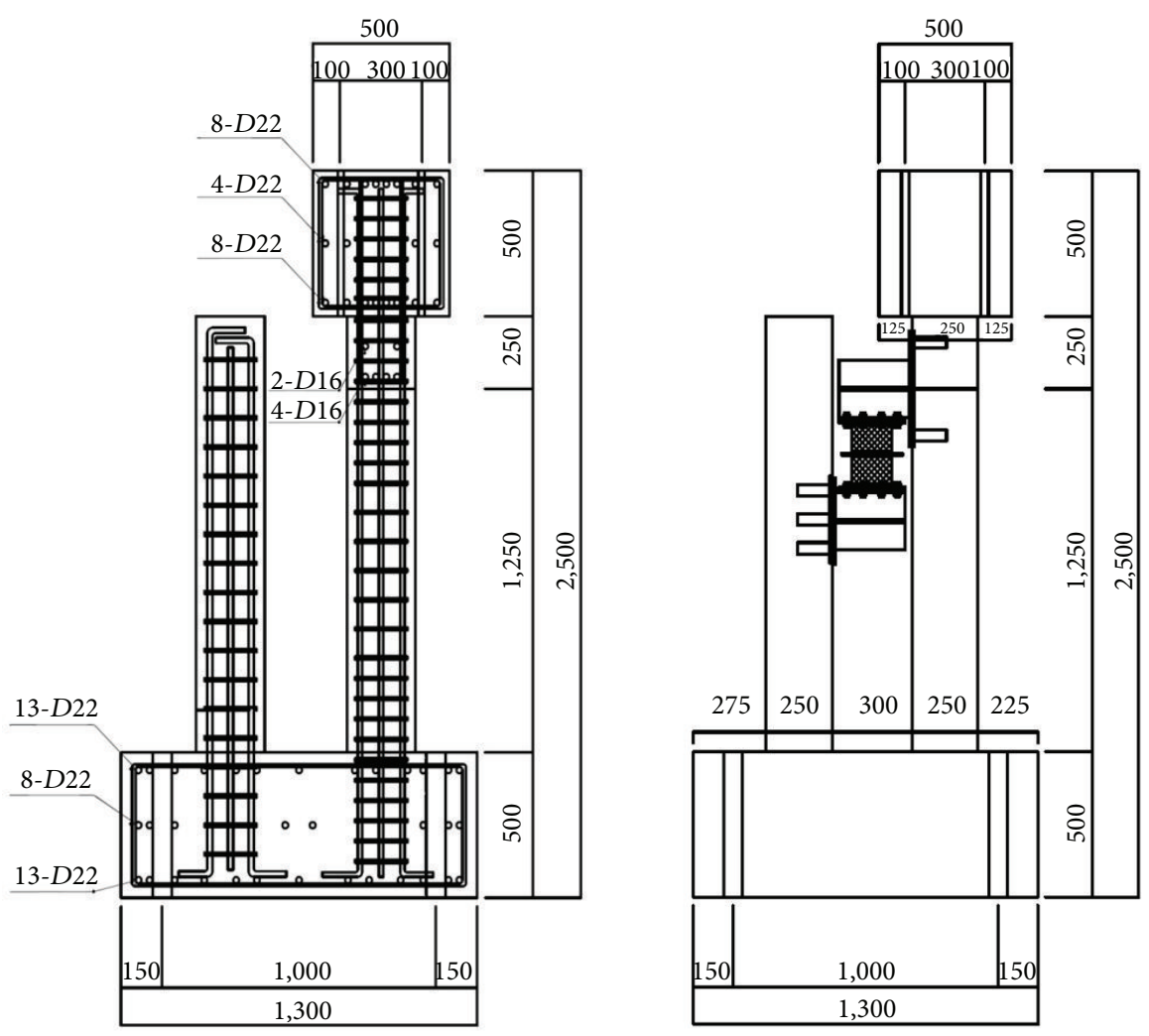

(e)

FIGURE 5: Configuration and details of test specimens: (a) rear view, (b) front view, and (c) inside view of specimen strengthened with a Kagome damper. (d) Details of control specimen and (e) specimen strengthened with a Kagome damper. 


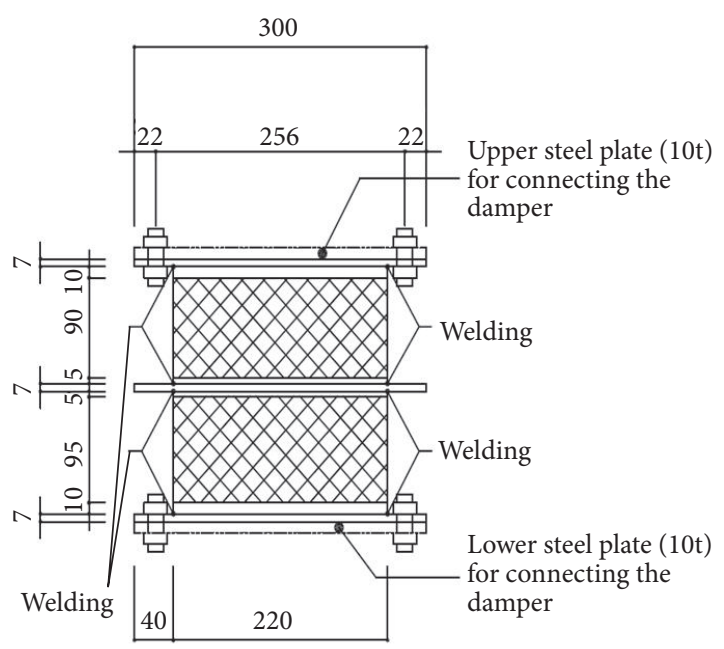

(a)

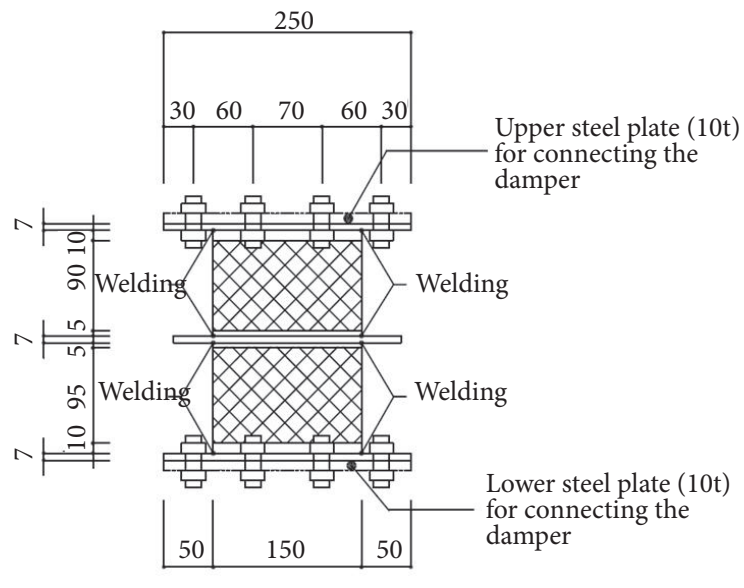

(c)

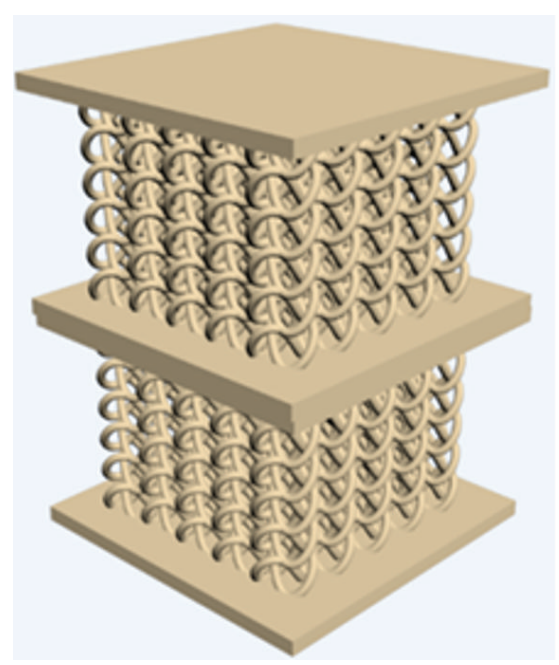

(b)

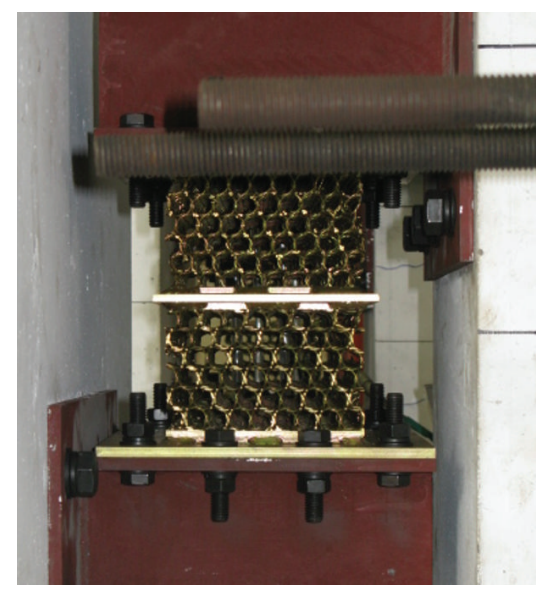

(d)

Figure 6: Configuration and details of the Kagome damper: (a) front view, (b) isometric view, and (c) side view. (d) Fabrication of the Kagome damper.

rate of loading. However, shake-table testing may be favored in cases where strain-rate effects are significant and/or in distributed parameter systems.

Experimental measurements are used to determine the structural restoring forces during the test. These measured forces are then used by the computer, together with a set of mathematical equations for the inertial response characteristics, to determine changes in the structural displacement that would occur as a consequence of the given ground acceleration. The procedure is superior to quasi-static testing because the nonlinear structural characteristics are based on instantaneous experimental feedback rather than on hypothetical mathematical models. Pseudodynamic testing differs from classical computer-based structural dynamic simulations, which depend on experimentally measured structural restoring forces rather than on structural restoring forces computed from a mathematical model.

4.2. Description of Pseudodynamic Testing System Used in This Study. A simplified schematic diagram of the pseudodynamic testing system used in this study is shown in Figure 7.
The system can be expressed as a single degree-of-freedom (SDF) structure. During the test, the computed displacement response is imposed on the specimen by hydraulic actuators. The actual restoring forces are physically measured from the test. This feedback value of restoring force is used by the control computer to calculate the displacement for the following time increment. Transformation of data is achieved using an analog-to-digital and digital-to-analog converter (DA-16A, Tokyo Soki Kenkyujo Company) [17]. Filtering and amplification are performed on all operations to ensure reliable results and accurate closed-loop control.

In this test, the Pseudodynamic Testing Program provided by MTS Systems Corporation [18] was used to calculate the displacement from the equation of motion of the SDF structural system, as given in (3), by the control computer:

$$
m \ddot{y}(t)+c \dot{y}(t)+r(t)=-m \ddot{u},
$$

where $y$ is the relative displacement of the mass with respect to its base, $c$ is the damping coefficient, $r$ is the hysteresis restoring force, and $\ddot{u}$ is the base acceleration. 


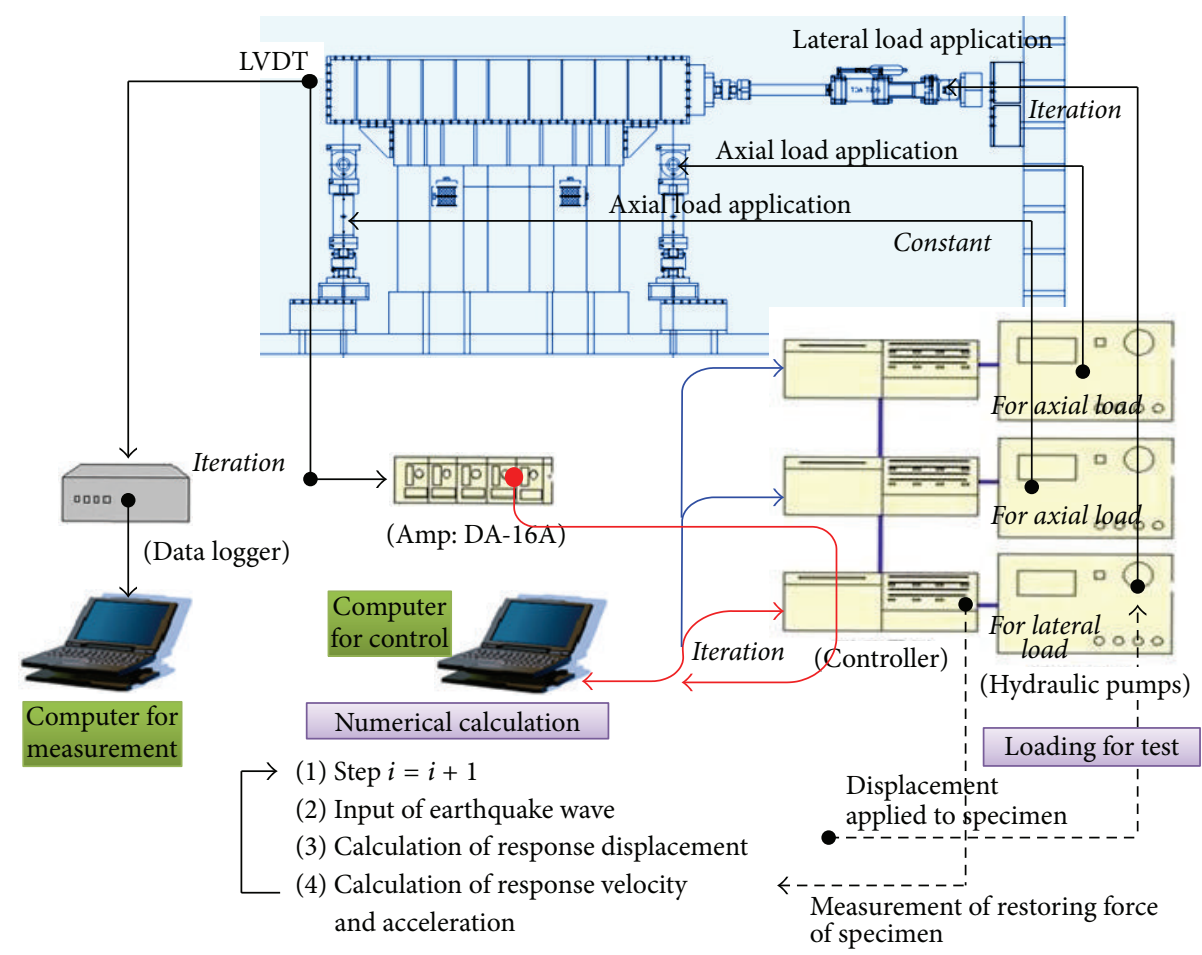

FIGURE 7: Simplified schematic diagram of the pseudodynamic testing system.

The time integration scheme adopted for solving the equation of motion was an adaptive time stepping algorithm developed by Shing et al. [19], based on the $\alpha$-method by Hilber et al. [20]. The algorithm to perform numerical integration of the pseudodynamic testing can be expressed in the following form:

$$
\begin{aligned}
& m a_{i+1}+(1+\alpha) c v_{i+1}-\alpha c v_{i}+(1+\alpha) r_{i+1}-\alpha r_{i} \\
& =(1+\alpha) f_{i+1}-\alpha f_{i}
\end{aligned}
$$

with

$$
\begin{aligned}
& y_{i+1}=y_{i}+\Delta t v_{i}+\Delta t^{2}\left[\left(\frac{1}{2}-\beta\right) a_{i}+\beta a_{i+1}\right], \\
& v_{i+1}=v_{i}+\Delta t\left[(1-\gamma) a_{i}+\gamma a_{i+1}\right],
\end{aligned}
$$

where $y_{i}, v_{i}$, and $a_{i}$ are the mass displacement, velocity, and acceleration at time equal to $i \Delta t$, respectively, $\Delta t$ is the integration time step, $r_{i}$ is the restoring force, and $f_{i}$ is the external force excitation (i.e., $-m \ddot{u}_{i}$ ). For a linearly elastic structure, $r_{i}=k y_{i}$, in which $k$ is the elastic stiffness of the structure. $\alpha, \beta$, and $\gamma$ are parameters that govern the numerical properties of the algorithm. The algorithm is unconditionally stable when $-0.5 \leq \alpha \leq 0, \beta=(1-\alpha)^{2} / 4$, and $\gamma=1 / 2-\alpha$.

Response displacement of the next time step was calculated using (3)-(5), based on the stiffness $(k)$, mass $(m)$, and the stiffness proportional damping coefficient $(c=$ $2 \xi \sqrt{k \cdot m}$ ), in which the damping ratio $\xi$ was assumed to be 0.03 (i.e., $3 \%$ of the critical damping value). Here, the initial stiffness (elastic stiffness) for the input data of the Pseudodynamic Testing Program was derived from the result of the cyclic loading test, as described later. A $2,000 \mathrm{kN}$ hydraulic actuator was used to apply the lateral load. The horizontal displacement for calculating response was measured with a $300 \mathrm{~mm}$ LVDT (Linear Variable Differential Transformer). Two columns were subjected to a constant vertical load of $210 \mathrm{kN}$, which is $10 \%$ of the nominal compressive strength of the concrete, using two $1,000 \mathrm{kN}$ oil jacks. The ground motion acceleration for the pseudodynamic test was the north-south (NS) ground motion recorded at El Centro during the 1940 Imperial Valley earthquake. As stated previously, the magnitude of the ground motion was normalized to acceleration values of $200 \mathrm{gal}$ and 300 gal, based on the seismic design code in Korea [9].

Before the pseudodynamic test, a cyclic loading test was carried out to estimate the ultimate and yield shear load-carrying capacity and deformation, as well as hysteresis in the lateral load-drift relationship of an $\mathrm{RC}$ frame strengthened with the KDEC system (CL-FK specimen), together with nonstrengthened frame (CL-F specimen). A cyclic loading scheme with predetermined displacement was used. The load cycles were designed to have antisymmetric moments in the lateral direction. The loading cycles were repeated three times at lateral drift angles $(R, \%)$ of $0.1 \%(1.25 \mathrm{~mm}), 0.2 \%(2.5 \mathrm{~mm}), 0.4 \%(5 \mathrm{~mm})$, $0.5 \%$ (6.25 mm), $0.67 \%$ (8.33 mm), $1 \%$ (12.5 mm), $1.33 \%$ (16.67 mm), 2\% (25 mm), 2.67\% (33.33 mm), 4\% (50 mm), and $5.68 \%(71.02 \mathrm{~mm})$. Figure 8 shows the experimental configuration for the pseudodynamic and cyclic loading tests. 


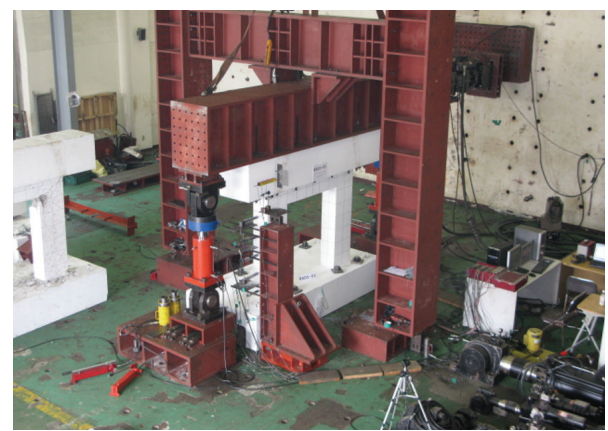

Figure 8: Test configuration.

\section{Crack and Failure Patterns}

The crack and failure patterns that appeared in the nonstrengthened control specimen (PD-F) and specimen reinforced with the KDEC system (PD-FK) during the pseudodynamic testing were investigated, as well as the CL-F and CL-FK specimens during the cyclic loading test. Both specimens following the pseudodynamic and cyclic loading tests failed in response to flexural strain. However, the failure pattern at the final stage of the control (PD-F and CL$\mathrm{F}$ ) and reinforced specimen (PD-FK and CL-FK) differed significantly. In the following discussion, we focus on the crack and failure patterns in terms of the lateral displacement.

5.1. Nonstrengthened Control Specimen (CL-F) for Cyclic Loading Test. The control specimen was designed based on the seismic design code in Korea so that it would exhibit flexural failure, as stated earlier. Figure 9 shows the crack patterns that were observed on the CL-F specimen following the final stages of the cyclic loading test. The first observed crack occurred at a positive load of $156 \mathrm{kN}$; a slight flexural crack appeared in both the bottom and the upper column faces after the fourth cycles at the second loading step $(R=$ $0.2 \%, 2.5 \mathrm{~mm}$ ). Cracking, however, was not observed in the center of either column. Flexural cracks extended into the middle of the column after step two. Following the ninth cycle at the third loading step $(R=0.4 \%, 5 \mathrm{~mm})$, with a load of both positive $303 \mathrm{kN}$ and negative $293 \mathrm{kN}$, diagonal shear cracks were observed at the top and bottom faces of the columns, including the middle faces.

When the applied load reached $399 \mathrm{kN}$, at the fifth positive loading step $(R=0.67 \%, 8.33 \mathrm{~mm})$, larger shear cracks appeared at the middle of the columns, with increased widths. After step five, many diagonal shear and flexural cracks with more increased widths, some of which were more than $5 \mathrm{~mm}$, were observed in all column faces. Following the 24 th positive loading cycle (the eighth loading step, $R=2 \%$, $25 \mathrm{~mm}$ ), we observed peeling failure due to shear forces from the concrete cover at the top faces of the columns. Flexural collapse occurred at the top of both columns following the application of a negative load of $318 \mathrm{kN}$, with a lateral drift of $50 \mathrm{~mm}(R=4 \%)$. The maximum load capacity of the nonstrengthened control CL-K specimen was a positive load of $530 \mathrm{kN}$, with a lateral drift of $25 \mathrm{~mm}(R=2 \%)$.

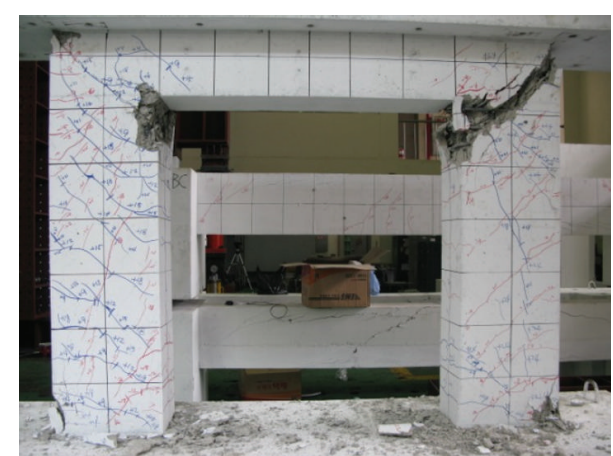

FIGURE 9: Cracks that appeared in the CL-F specimen during cyclic loading.

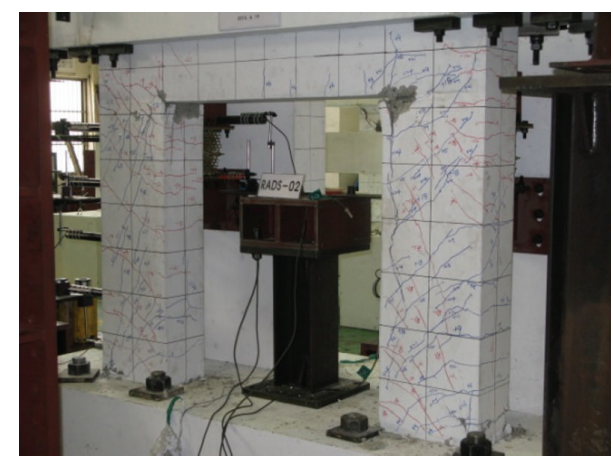

FIGURE 10: Cracks that appeared in the CL-FK specimen during cyclic loading.

5.2. Specimen Strengthened with KDEC System (CL-FK) for Cyclic Loading Test. Figure 10 shows a photograph of the CLFK specimen following the cyclic loading test. The CL-FK specimen featured the original RC frame strengthened by the external connection methodology using the wire-woven bulk Kagome truss, as shown in Figure 5. The first crack was observed with a positive load of $133 \mathrm{kN}$ and with a lateral drift of $1.25 \mathrm{~mm}$. This was a slight flexural crack, which appeared on the top of the column faces after three cycles of the first loading step $(R=0.1 \%)$. Flexural cracks also appeared following the second and third loading steps, and diagonal shear cracks appeared following the third loading step $(R=$ $0.4 \%, 5 \mathrm{~mm}$ ) with a positive load of $320 \mathrm{kN}$. The shear cracks increased in number and extended into the middle of both columns at the 15th cycle of the fourth loading step $(R=$ $0.5 \%, 6.25 \mathrm{~mm}$ ). Compared with the control CL-F specimen, however, there were a small number of cracks, which were less wide.

Following the 22nd positive loading cycle (8th loading step, $R=2 \%, 25 \mathrm{~mm}$ ), the strength capacity did not increase, and a maximum load was reached. The maximum load capacity of the CL-FK specimen was a positive load of $575 \mathrm{kN}$. When the applied displacement reached the 25th cycle $(R=$ $2.67 \%, 33.33 \mathrm{~mm}$ ), the lateral load was gradually reduced, and flexural failure occurred at the top and bottom of both columns under a negative load of $477 \mathrm{kN}$, with a lateral drift of $50 \mathrm{~mm}(R=4 \%, 50 \mathrm{~mm})$. 


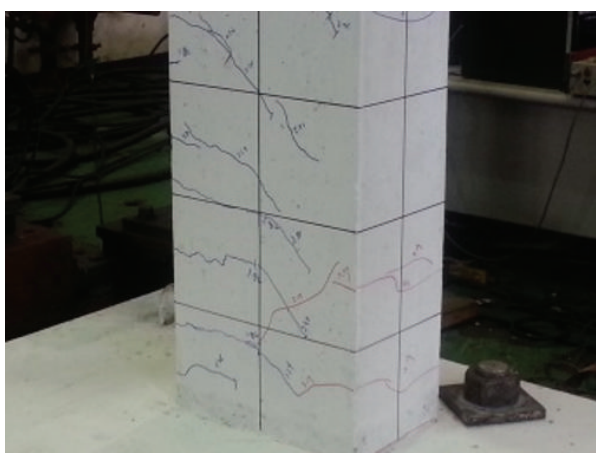

(a)

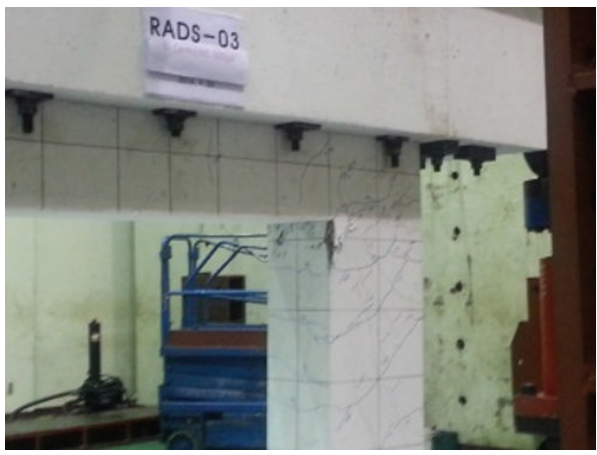

(c)

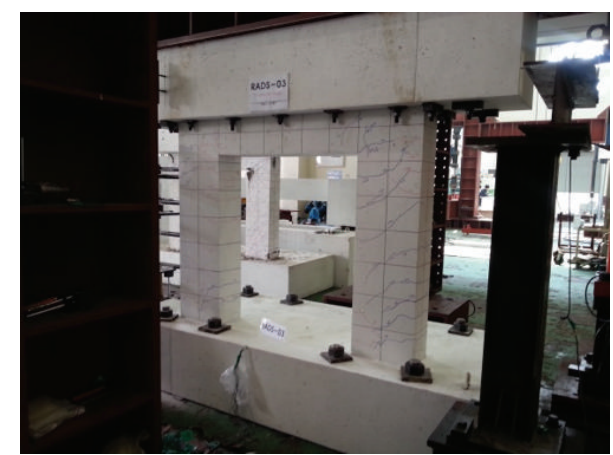

(b)

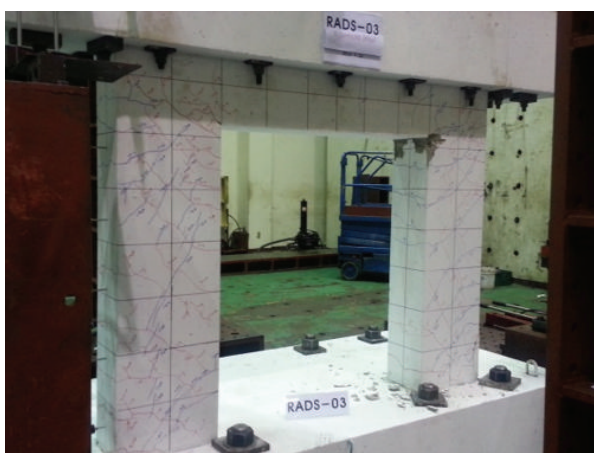

(d)

FIGURE 11: Cracks that appeared in the PD-F specimen during pseudodynamic testing: (a) $2.7 \mathrm{~s}$ with lateral displacement of $12 \mathrm{~mm}$ in 200 gal, (b) the final stage (4 s) in $200 \mathrm{gal}$, (c) $2.12 \mathrm{~s}$ with lateral displacement of $-28.7 \mathrm{~mm}$ in $300 \mathrm{gal}$, and (d) the final stage (4s) in 300 gal.

5.3. Nonstrengthened Control Specimen (PD-F) for Pseudodynamic Test. Figure 11 shows the crack pattern that was observed in the PD-F specimen during the pseudodynamic testing, performed by applying moderate and severe earthquake ground motions of $200 \mathrm{gal}$ and $300 \mathrm{gal}$ (El Centro, NS), as well as in the final stages. The first crack was observed with a positive load of $159 \mathrm{kN}$ and with a lateral drift of $2.6 \mathrm{~mm}$ in $\sim 1.5 \mathrm{~s}$ in the case of an earthquake ground motion of 200 gal. This was a slight flexural crack, which appeared in both the bottom and the upper column faces. Flexural cracks extended into the middle of the column after $1.8 \mathrm{~s}$, and, following $2.17 \mathrm{~s}$, with a negative load of $397 \mathrm{kN}$ having lateral displacement of $9.5 \mathrm{~mm}$, diagonal shear cracks were observed at the top and bottom faces of the columns. The shear cracks increased in number and extended into the middle of both columns after $2.3 \mathrm{~s}$. The maximum earthquake response of the $\mathrm{PD}-\mathrm{F}$ control specimen tested using an earthquake ground motion of 200 gal was observed at $2.7 \mathrm{~s}$ with a positive load of $447 \mathrm{kN}$, with lateral displacement of $12 \mathrm{~mm}$.

In the case of severe earthquake ground motion of 300 gal, after $\sim 1.53 \mathrm{~s}$ with a negative load of $414 \mathrm{kN}$ having lateral displacement of $11.5 \mathrm{~mm}$, large visible shear cracks were observed on all faces of the columns. The shear cracks increased in number and extended in width after $1.83 \mathrm{~s}$ with lateral displacement of $19.3 \mathrm{~mm}$. Following $2.12 \mathrm{~s}$ with lateral displacement of $28.7 \mathrm{~mm}$, we observed peeling failure due to earthquake shear forces from the concrete cover at the top faces of the columns. Flexural collapse occurred at the top of both columns in $2.2 \mathrm{~s}$, following the application of a negative load of $506 \mathrm{kN}$, with lateral displacement of $40.3 \mathrm{~mm}$.

\subsection{Specimen Strengthened with KDEC System (PD-FK) for} Pseudodynamic Test. The PD-FK specimen featured the RC frame strengthened by the external connection methodology using the wire-woven bulk Kagome truss (Figure 5). Figure 12 shows the crack sequence that was observed in the PD-FK specimen during the pseudodynamic testing, using normalized acceleration values of $200 \mathrm{gal}$ and $300 \mathrm{gal}$, based on the north-south (NS) ground motion recorded at El Centro. In the case of an earthquake ground motion of 200 gal, a slight flexural crack was first observed in the upper faces of columns with a negative load of $105 \mathrm{kN}$ and with lateral displacement of $1.7 \mathrm{~mm}$ in $\sim 1.5 \mathrm{~s}$. Flexural cracks extended into the middle of the column after $2.2 \mathrm{~s}$ with lateral negative displacement of $5.6 \mathrm{~mm}$. However, the flexural crack was still slight and no shear crack was observed; only a slight flexural crack was maintained at the maximum earthquake response, which occurred at $2.65 \mathrm{~s}$ with a positive load of $406 \mathrm{kN}$ and lateral displacement of $7.5 \mathrm{~mm}$. The PD-FK specimen sustained light damage with a slight flexural crack, whereas the PD-F control specimen showed moderate damage with larger flexural and shear cracks. Thus, the external connection methodology using the wire-woven bulk Kagome truss proposed in this study showed a good reinforcement effect in terms of degree of damage.

When an earthquake ground motion of 300 gal was used, after $1.8 \mathrm{~s}$, with a positive load of $536 \mathrm{kN}$, having lateral 
TABLE 5: Results of mechanical characterizations of test specimens following the cyclic loading test.

\begin{tabular}{|c|c|c|c|c|c|c|}
\hline Specimen & Load direction & $\begin{array}{l}\text { Yield shear } \\
\text { strength } \\
V_{y}(\mathrm{kN})\end{array}$ & $\begin{array}{c}\text { Maximum shear } \\
\text { strength } \\
V_{\max }(\mathrm{kN})\end{array}$ & $\begin{array}{c}\text { Displacement at } \\
\text { the yield point } \\
\Delta_{y}(\mathrm{~mm})\end{array}$ & $\begin{array}{c}\text { Displacement at } \\
\text { the maximum } \\
\text { point } \\
\Delta_{\max }(\mathrm{mm})\end{array}$ & Failure mode \\
\hline \multirow{2}{*}{ CL-F } & Positive & 468 & 530 & 12.5 & 25 & \multirow{2}{*}{ Flexural failure } \\
\hline & Negative & -462 & -531 & -12.3 & -24.5 & \\
\hline \multirow{2}{*}{ CL-FK } & Positive & 486 & 575 & 12.5 & 25.2 & \multirow{2}{*}{ Flexure } \\
\hline & Negative & -485 & -570 & 12.1 & 24.3 & \\
\hline
\end{tabular}

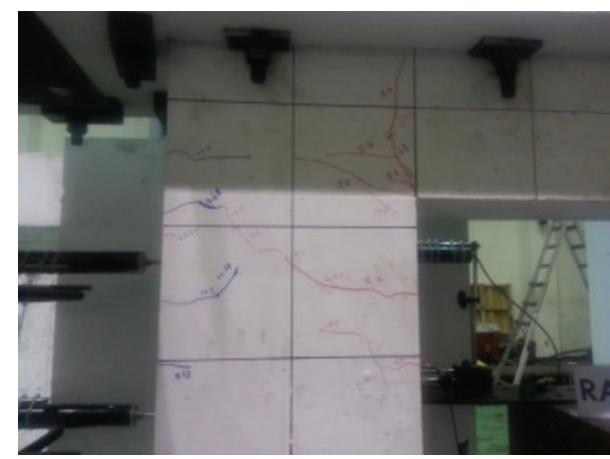

(a)

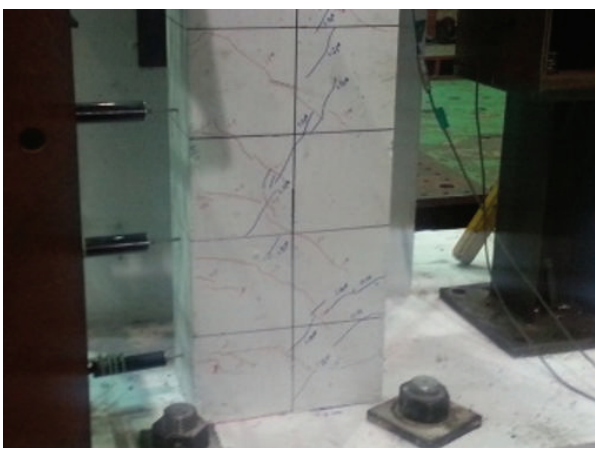

(c)

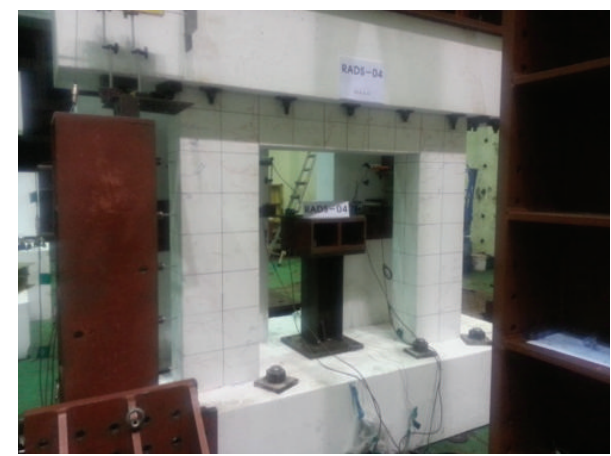

(b)

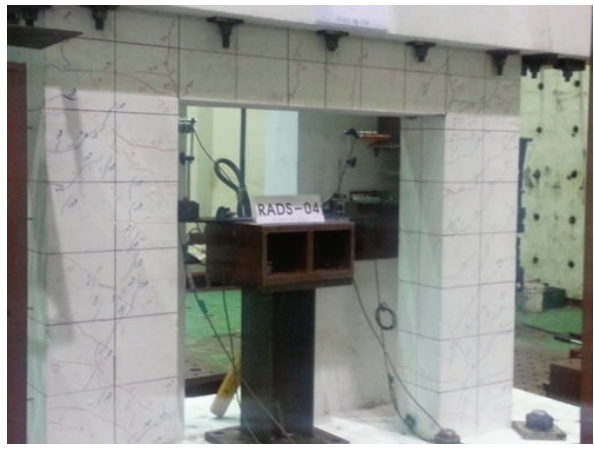

(d)

FIGURE 12: Cracks that appeared in the PD-FK specimen during pseudodynamic testing: (a) $2.7 \mathrm{~s}$ with lateral displacement of $7.5 \mathrm{~mm}$ in 200 gal, (b) the final stage (4 s) in 200 gal, (c) $2.7 \mathrm{~s}$ with lateral displacement of $-25 \mathrm{~mm}$ in $300 \mathrm{gal}$, and (d) the final stage (4 s) in 300 gal.

displacement of $16 \mathrm{~mm}$, diagonal shear cracks were observed at the top and bottom faces of the columns. The shear cracks increased in number and extended into the middle of both columns after $2.1 \mathrm{~s}$. Compared with the control PDF specimen, however, there were a smaller number of cracks that were not as wide. The maximum earthquake response of the PD-FK specimen occurred at $2.17 \mathrm{~s}$, but no peeling failure of the concrete cover was observed. As a result, the reinforced PD-FK specimen showed moderate damage with flexural and shear cracks at a severe earthquake level of $300 \mathrm{gal}$; the strengthening effects were verified in a comparison with a nonstrengthened control PD-F specimen in which heavy earthquake damage with flexural failure at the upper columns was observed.

\section{Load-Displacement Relationships and Earthquake Damage Degree Estimates}

Figures 13 and 14 represent the load-displacement curves that were measured on the CL-F control and the strengthened CL-FK specimens during the cyclic loading test, respectively. Table 5 lists the results of mechanical characteristics in terms of shear strengths and displacement with positive and negative loads for both specimens. The yield strengths and displacement of the specimens were described using Park's definition, which is the most realistic definition available for the yield displacement for RC structures [21]. The yield displacement of the equivalent elastoplastic system with reduced stiffness is given by the secant stiffness at $75 \%$ of the ultimate lateral load of the system. 
TABLE 6: Comparisons of response strength, response displacement, and earthquake damage degree following the pseudodynamic test.

\begin{tabular}{|c|c|c|c|c|c|}
\hline Specimen & $\begin{array}{c}\text { Inputted } \\
\text { earthquake } \\
\text { intensities (gal) }\end{array}$ & $\begin{array}{c}\text { Maximum } \\
\text { response } \\
\text { strength } \\
V_{u}(\mathrm{kN})\end{array}$ & $\begin{array}{c}\text { Response } \\
\text { displacement at } \\
\text { maximum point } \\
\Delta_{\max }(\mathrm{mm})\end{array}$ & $\begin{array}{l}\text { Failure mode at } \\
\text { ultimate state }\end{array}$ & $\begin{array}{c}\text { Earthquake } \\
\text { damage degree* }\end{array}$ \\
\hline \multirow{2}{*}{ PD-RF } & 200 & 446.7 & 12 & Flexure & Moderate \\
\hline & 300 & 506.3 & 40.3 & Flexure & Heavy \\
\hline \multirow{2}{*}{ PD-RFKD } & 200 & 406 & 7.5 & Flexure & Light \\
\hline & 300 & 630.7 & 25 & Flexure & Moderate \\
\hline
\end{tabular}

${ }^{*}$ Earthquake damage degree was estimated based on the research results of JBDPA [10] and Maeda et al. [11].

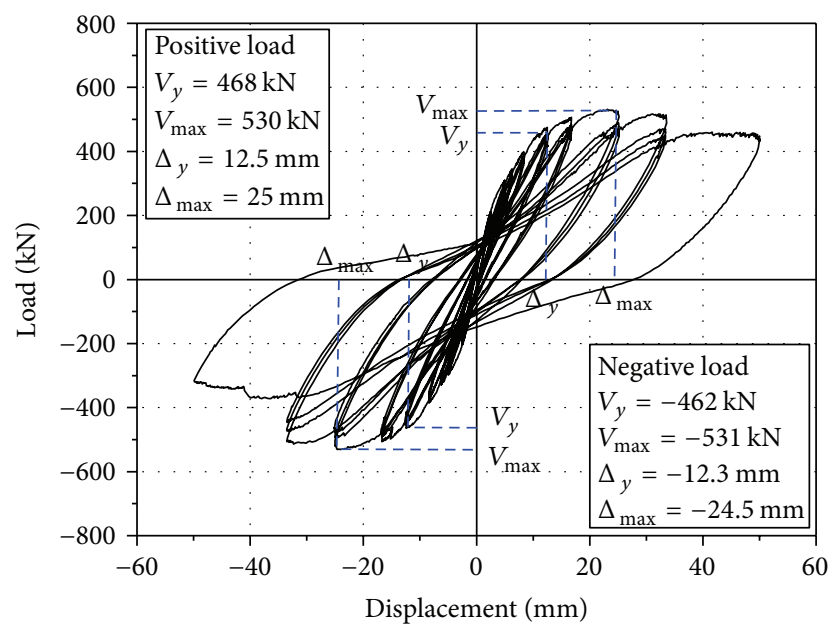

$V_{\max }$ : maximum shear strength

$\Delta_{\max }:$ displacement at the maximum point

$V_{y}$ : yield shear strength

$\Delta_{y}$ : displacement at the yield point

FIGURE 13: Lateral load-displacement curve for the CL-F specimen.

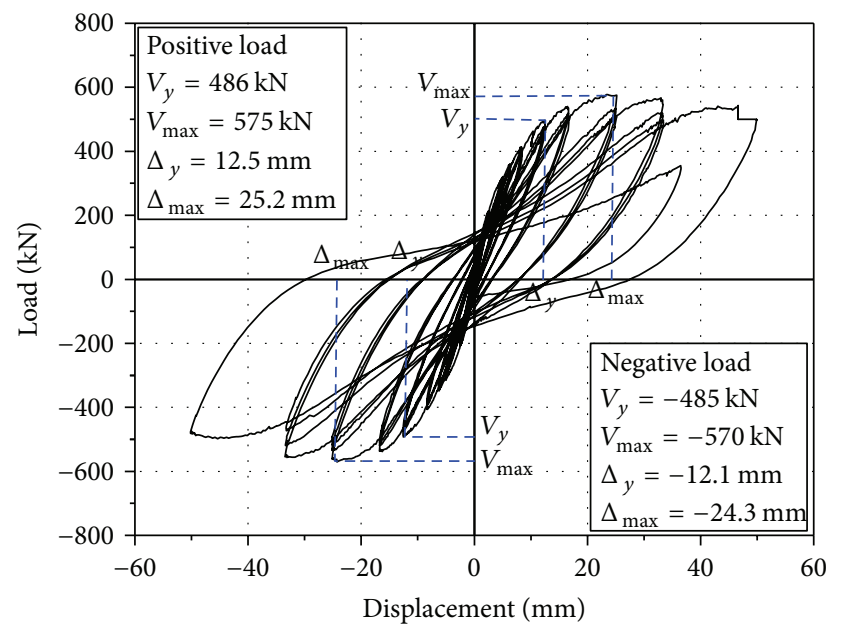

$V_{\text {max }}:$ maximum shear strength

$\Delta_{\text {max }}$ : displacement at the maximum point

$V_{y}$ : yield shear strength

$\Delta_{y}$ : displacement at the yield point

FIGURE 14: Lateral load-displacement curve for the CL-FK specimen.
The maximum load capacity of the nonstrengthened control CL-K specimen was a positive load of $530 \mathrm{kN}$, with a lateral drift of $25 \mathrm{~mm}(R=2 \%)$, as shown in Figure 13 and Table 5 . The yield occurred at a positive load of $468 \mathrm{kN}$, with a lateral drift of $12.5 \mathrm{~mm}(R=1 \%)$ using Park's definition. As presented in Figure 14 and Table 5, the maximum load capacity of the CL-FK specimen reinforced with the KDEC system was a positive load of $575 \mathrm{kN}$, with a lateral drift of $25.2 \mathrm{~mm}(R=2 \%)$. The yielding load was a positive load of $486 \mathrm{kN}$, with a lateral drift of $12.5 \mathrm{~mm}(R=1 \%)$. The strengthened CL-FK specimen showed a load increase of $\sim 18 \mathrm{kN}$ and $45 \mathrm{kN}$ (i.e., $4 \%$ and $10 \%$ larger) compared with the CL-F control specimen. However, both displacement values at the yield and the maximum point of the CL-FL strengthened specimen were similar to those of the control CL-F specimen.

Figure 15 shows the lateral response load-displacement relationship of the PD-F control specimen during the pseudodynamic test with respect to $200 \mathrm{gal}$ and $300 \mathrm{gal}$ of the north-south (NS) ground motion recorded at El Centro during the 1940 Imperial Valley earthquake. In the figure, an envelope curve of the lateral load-displacement relationship for the CL-F control specimen following the cyclic loading test is also shown. Figure 16 shows the lateral response load-displacement relationship of the PD-FK specimen reinforced with the KDEC system during the pseudodynamic test with respect to $200 \mathrm{gal}$ and $300 \mathrm{gal}$, together with an envelope curve of the lateral load-displacement relationship for the CL-FK reinforced specimen following the cyclic loading test. Table 6 presents comparisons of the maximum response strength, maximum response displacement, and earthquake damage degrees following the pseudodynamic test of PD-F and PD-FK specimens at $200 \mathrm{gal}$ and $300 \mathrm{gal}$. Here, earthquake damage degrees were estimated based on the technique for postearthquake damage evaluation of RC buildings, proposed by JBDPA [10] and Maeda et al. [11].

The maximum earthquake response of PD-F control specimen with respect to an earthquake ground motion of 200 gal was observed at a load of $447 \mathrm{kN}$ with lateral displacement of $12 \mathrm{~mm}$, which was evaluated as moderate earthquake damage, based on the technique for postearthquake damage evaluation [11]. The same control specimen, with respect to a ground motion of 300 gal, showed a maximum response strength of $506 \mathrm{kN}$ with lateral displacement of $40.3 \mathrm{~mm}$ that exceeded approximately the quadruple drift, compared with 


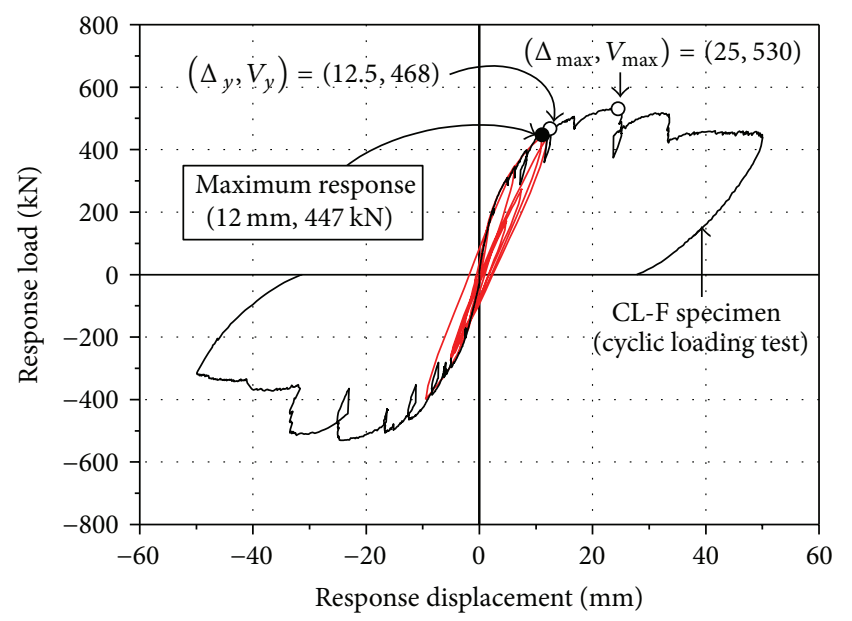

- PD-F control specimen for pseudodynamic test (200 gal)

(a)

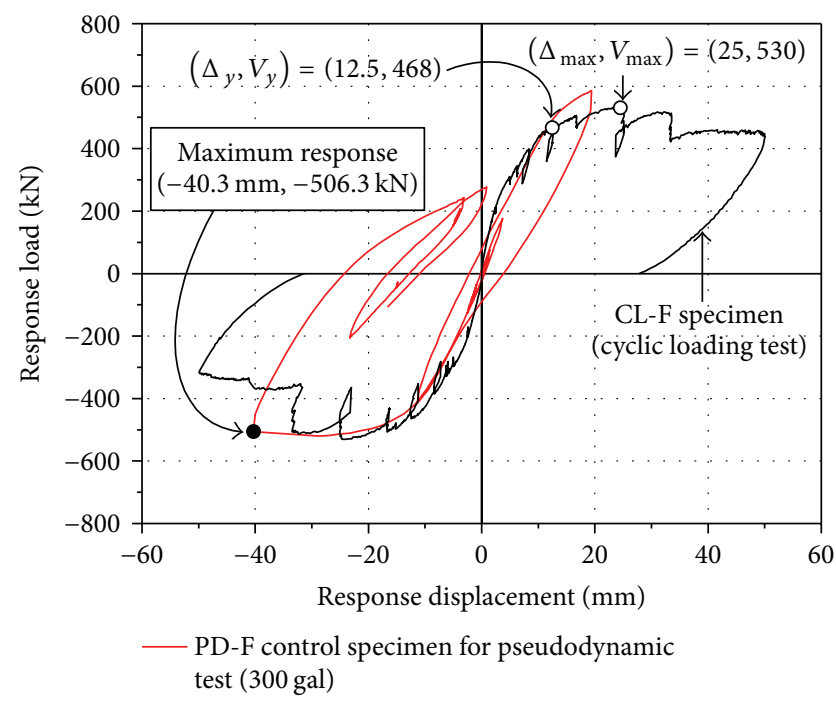

(b)

FIGURE 15: Lateral response load-displacement relationships of the PD-F control specimen during pseudodynamic test: (a) 200 gal and (b) 300 gal.

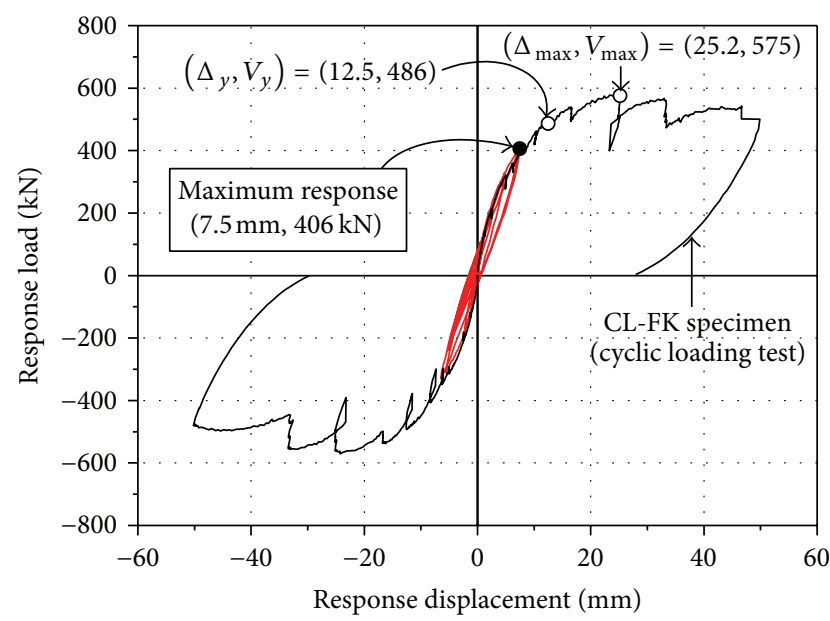

- PD-FK specimen strengthened with KDEC for pseudodynamic test $(200 \mathrm{gal})$

(a)

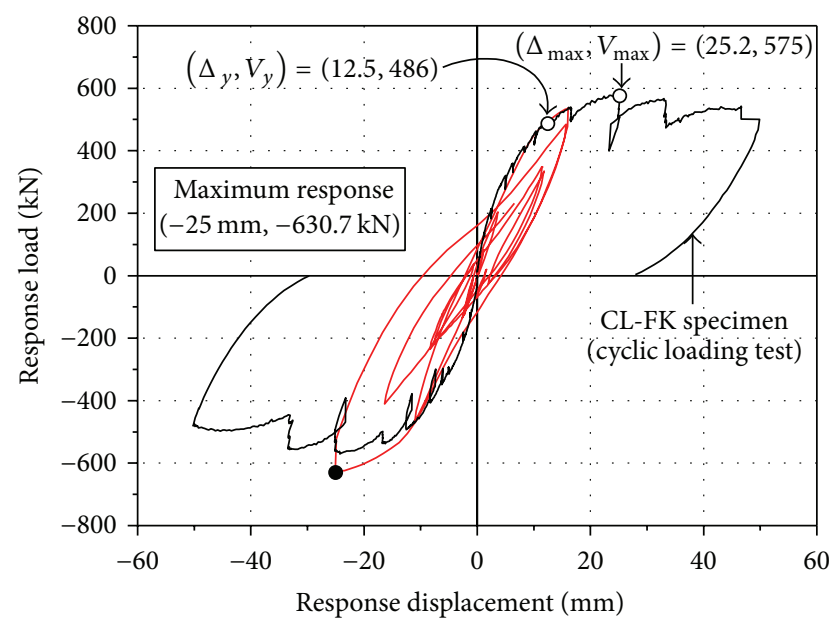

- PD-FK specimen strengthened with KDEC for pseudodynamic test (300 gal)

(b)

FIGURE 16: Lateral response load-displacement relationships of the PD-FK specimen strengthened with the KDEC system during pseudodynamic test: (a) 200 gal and (b) 300 gal.

that at the yield point of $\Delta_{y}=12.5 \mathrm{~mm}$ of CL-F specimen during the cyclic loading test. Eventually, the control specimen sustained heavy damage during an earthquake ground motion of 300 gal.

In the case of an earthquake ground motion of $200 \mathrm{gal}$, the PD-FK specimen reinforced using the KDEC system proposed in this study showed a maximum response strength of $406 \mathrm{kN}$ with displacement of $7.5 \mathrm{~mm}$, suffering light damage with a slight flexural crack, whereas the PD-F control specimen sustained moderate damage with larger flexural and shear cracks. When a severe earthquake ground motion of 300 gal was applied to the PD-FK specimen, the maximum earthquake response appeared at a load of $631 \mathrm{kN}$ with lateral displacement of $25.2 \mathrm{~mm}$, which was similar to a result of $\Delta_{\max }=25 \mathrm{~mm}$ of the CL-FK specimen during the cyclic loading test. The earthquake damage degree was estimated as moderate damage. These results revealed that the external connection methodology using the wire-woven bulk Kagome truss is a useful strategy for seismic strengthening of a building system.

\section{Response Displacement-Time History Relationships and Response Ductility}

Figures 17 and 18 present comparisons between response displacement-time history relationships of the PD-F control 


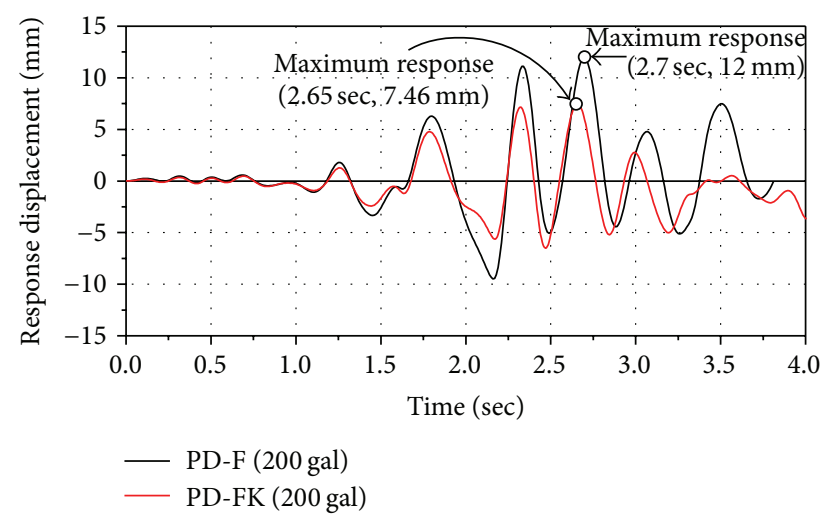

FIGURE 17: Comparisons between response displacement-time history relationships of the PDF and PD-FK specimens during pseudodynamic tests for 200 gal.

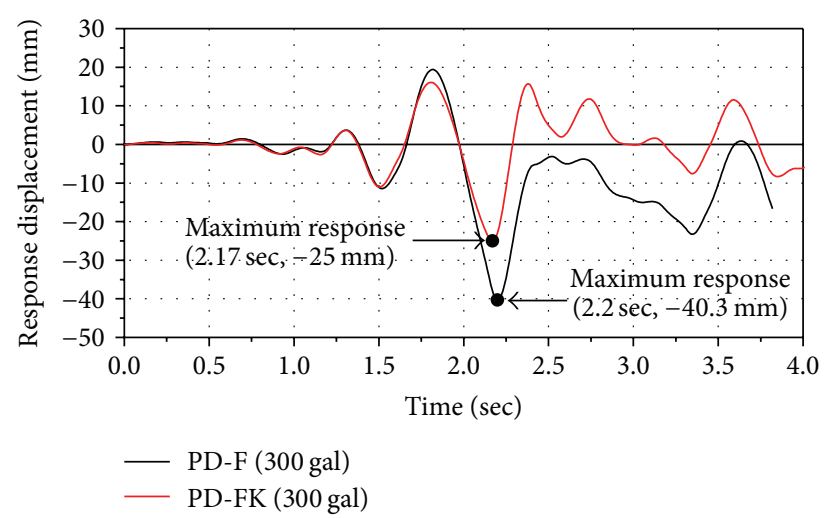

FIGURE 18: Comparisons between response displacement-time history relationships of the PDF and PD-FK specimens during pseudodynamic tests for 300 gal.

and the PD-FK reinforcement specimens during the pseudodynamic test with respect to earthquake ground motions of $200 \mathrm{gal}$ and $300 \mathrm{gal}$, respectively. When an earthquake ground motion of $200 \mathrm{gal}$ was used, the maximum response displacement of the PD-F specimen was observed at $2.7 \mathrm{~s}$, with a lateral drift of $12 \mathrm{~mm}$, whereas that of the PD-FK reinforcement specimen occurred at $2.65 \mathrm{~s}$ with a drift of $7.5 \mathrm{~mm}$. In the case of the severe earthquake level, 300 gal, for the PD-F control specimen, the maximum response occurred following $\sim 2.2 \mathrm{~s}$ with lateral displacement of $40.3 \mathrm{~mm}$, which resulted in the flexural collapse of both columns. The strengthened PD-FK specimen, however, suffered moderate damage, showing maximum response displacement of $25 \mathrm{~mm}$ at $2.17 \mathrm{~s}$.

The earthquake response quantity of primary interest is the ductility ratio, $\mu$, defined as the ratio of maximum response displacement $\left(\Delta_{\max }\right)$ to the yield displacement point $\left(\Delta_{y}\right)$. The ductility ratio, $\mu$, can be expressed as

$$
\mu=\frac{\Delta_{\max }}{\Delta_{y}} .
$$

TABLE 7: Comparison of response ductility.

\begin{tabular}{|c|c|c|}
\hline \multirow[t]{2}{*}{$\begin{array}{l}\text { Earthquake } \\
\text { intensities (gal) }\end{array}$} & \multicolumn{2}{|c|}{$\begin{array}{c}\text { Ductility responses of pseudodynamic } \\
\text { testing }(\mu)^{* 1}\end{array}$} \\
\hline & PD-F & \\
\hline 200 & $0.96(12)^{* 2}$ & $0.6(7.5)^{* 2}$ \\
\hline $300 \mathrm{~g}$ & $3.3(40.3$ & $2(25)^{* 2}$ \\
\hline \multicolumn{3}{|c|}{$\begin{array}{l}{ }^{* 1} \text { Ductility is defined as the ratio of the maximum response displacement } \\
\left(\Delta_{\text {max }}\right) \text { of the PD-F and PD-FK specimens shown in Figures } 17 \text { and } 18 \text { to the } \\
\text { yield displacement }\left(\Delta_{y}\right) \text { of CL-F and CL-FK specimens, following the cyclic } \\
\text { loading test, presented in Figures } 13 \text { and } 14: \text { that is, } \mu=\Delta_{\max } / \Delta_{y} \text {. } \\
{ }^{* 2} \text { Values in parentheses indicate the maximum response displacement } \\
(\mathrm{mm}) \text {. }\end{array}$} \\
\hline
\end{tabular}

Table 7 shows comparisons of response ductility $(\mu)$ between the PD-F control and the PDFK reinforced specimens with respect to ground acceleration values of $200 \mathrm{gal}$ and 300 gal. The ductility ratio, represented in the table, was calculated based on (6) as follows: $\Delta_{\max }=$ the maximum response displacement of the PD-F and PD-FK specimens shown in Figures 17 and 18 and $\Delta_{y}=$ the yield displacement of CL-F and CL-FK specimens following the cyclic loading test, depicted in Figures 13 and 14, respectively.

As shown in Table 7, the PD-F control specimen had a ductility ratio of $\mu=0.96$ in the case of the 200 gal earthquake. When the earthquake ground motion of 300 gal was used for the PD-F specimen, the ductility ratio was calculated as $\mu=3.3$, which corresponds to heavy damage. The PD-FK strengthened with the KDEC system showed a ductility ratio of $\mu=0.6$ with respect to 200 gal. In the case of $300 \mathrm{gal}$, the reinforced specimen showed $\mu=2.0$, which corresponds to moderate earthquake damage. When the same levels of earthquake ground motions were used, the Kagomereinforced specimen reduced the ductility response by $40 \%$, compared with the nonstrengthened control specimen.

\section{Concluding Remarks}

We have described a new seismic retrofitting approach, which is an external connection methodology using a wirewoven bulk Kagome truss (KDEC system) that dissipates earthquake energy by a dynamic interaction among an existing building structure, a support structure, and a wirewoven bulk Kagome damper installed between them. An existing RC frame building was selected to assess the seismic strengthening effect of the KDEC system proposed in this study. First, a preliminary dynamic analysis was carried out to determine the optimum structural properties of the support and damper for the KDEC system, where the size of the Kagome damper, the height of support, and the ratio of the elastic modulus between the existing building and support were set as analysis variables. Test specimens strengthened with the KDEC system were designed and fabricated based on the results of the preliminary analysis.

Pseudodynamic and cyclic loading tests were carried out to verify the seismic strengthening effects of the proposed KDEC method compared to the original control frame in terms of the lateral load-displacement capacities, maximum 
response strength, response ductility, and earthquake damage degree under the levels of earthquake specified by the seismic design code in Korea. Test results revealed that the proposed Kagome damper system externally installed in the RC frame effectively dissipated the earthquake energy and was capable of marked resistance under a large-scale earthquake. The major results of this work can be summarized as follows.

(a) The preliminary dynamic analysis showed that the support scaled using a five-story structure with a ratio of elastic modulus of $\mathrm{EM}=1: 10$ and a cross section of the damper of $400 \times 400 \mathrm{~mm}$ was the "best" result for strengthening the existing RC frame using the $\mathrm{KDEC}$ system proposed in this study.

(b) The lateral load-displacement relationships following the cyclic loading test revealed that the strengthened CL-FK specimen had a maximum load of $575 \mathrm{kN}$ with a lateral drift of $25 \mathrm{~mm}(R=2 \%)$, representing a load increase of $\sim 10 \%$ larger than the CL-F control specimen that showed $530 \mathrm{kN}$ with a lateral drift of $25 \mathrm{~mm}(R=2 \%)$; however, the displacement capacities of both specimens were similar.

(c) The results of the pseudodynamic test with respect to an earthquake ground motion of 200 gal showed that the maximum earthquake response of the PD-F control specimen was seen at a load of $447 \mathrm{kN}$ with lateral displacement of $12 \mathrm{~mm}$, corresponding to moderate earthquake damage. In the case of a ground motion of 300 gal, the same control specimen showed a maximum response strength of $506 \mathrm{kN}$ with lateral displacement of $40.3 \mathrm{~mm}$ that exceeded approximately quadruple drift, compared with the displacement at the yield point of $\Delta_{y}=12.5 \mathrm{~mm}$ of CL-F specimen during the cyclic loading test. The control specimen sustained heavy damage during the earthquake ground motion of 300 gal.

(d) In the case of an earthquake ground motion of 200 gal, the PD-FK specimen reinforced using the KDEC system showed a maximum response strength of $406 \mathrm{kN}$ with displacement of $7.5 \mathrm{~mm}$, suffering light damage with the slight flexural cracks, whereas the PD-F control specimen sustained moderate damage with larger flexural and shear cracks. When a severe earthquake ground motion of 300 gal was used with the PD-FK specimen, the maximum earthquake response appeared at a load of $631 \mathrm{kN}$ with lateral displacement of $25.2 \mathrm{~mm}$, which was similar to the result of $\Delta_{\max }=25 \mathrm{~mm}$ of the CL-FK specimen during the cyclic loading test. The earthquake damage degree was estimated as moderate.

(e) The ductility ratio $(\mu)$, defined as the ratio of maximum response displacement during the pseudodynamic test to the yield displacement following the cyclic loading test, of the PD-F control specimen was calculated as $\mu=0.96$ (moderate damage) and $\mu=3.3$ (heavy damage) with respect to the 200 gal and 300 gal earthquake levels, respectively. The PD-FK strengthened with the KDEC system showed ductility ratios of $\mu=0.6$ (slight damage) and $\mu=2.0$ (medium damage) with respect to 200 gal and 300 gal earthquake levels, respectively. With the same earthquake ground motions, the Kagome-reinforced specimen reduced the ductility response by $40 \%$, compared with the nonstrengthened control specimen.

(f) These results showed that the external connection methodology using the wire-woven bulk Kagome truss proposed in this study as a passive damper system was capable of effectively absorbing earthquake energy applied to the building structures. This research, however, was focused on an experimental investigation to study the applicability of a new type of external connection methodology using the Kagome passive damper to strengthen an existing building system. As a recommendation for future work, additional theoretical studies, including a nonlinear dynamic analysis methodology for buildings being designed using the Kagome damper external connection system, are needed to justify the seismic strengthening design of existing structural systems, as well as design new structures.

\section{Competing Interests}

The authors declare no competing interests.

\section{Acknowledgments}

This work was supported by a grant (15CTAP-C097490-01) from the Technology Advancement Research Program and a grant (14RERP-B082884-01) from the Housing Environment Research Project, funded by the Ministry of Land, Infrastructure, and Transport Affairs of the Korean government.

\section{References}

[1] ASCE, "Minimum design loads for buildings and other structures," ASCE 7-10, American Society of Civil Engineers, 2010.

[2] AIJ, Standard for Structural Calculation of Reinforced Concrete Structures, Architectural Institute of Japan, 2010.

[3] ACI 318-14 and ACI 318R-14, Building Code Requirements for Structural Concrete and Commentary on Building Code Requirements for Structural Concrete, American Concrete Institute, 2014.

[4] J. Marko, D. Thambiratnam, and N. Perera, "Influence of damping systems on building structures subject to seismic effects," Engineering Structures, vol. 26, no. 13, pp. 1939-1956, 2004.

[5] J. S. Hwang, S. C. Park, and K. J. Kang, "A study on the hysteresis properties and mathematical model of Kagome truss damper," Journal of Architectural Institute of Korea, vol. 29, no. 9, pp. 2129, 2013.

[6] H. N. G. Wadley, N. A. Fleck, and A. G. Evans, "Fabrication and structural performance of periodic cellular metal sandwich structures," Composites Science and Technology, vol. 63, no. 16, pp. 2331-2343, 2003.

[7] Y.-H. Lee, B.-K. Lee, I. S. Jeon, and K.-J. Kang, "Wire-woven bulk Kagome truss cores," Acta Materialia, vol. 55, no. 18, pp. 6084-6094, 2007.

[8] Korea Land \& Housing Corporation, Jinju, South Korea, http:// www.lh.or.kr/.

[9] KBC-2009, Korea Building Code, Ministry of Land, Infrastructure and Transport, 2009.

[10] JBDPA, Standard for Damage Level Classification, Japan Building Disaster Prevention Association, Tokyo, Japan, 2001.

[11] M. Maeda, Y. Nakano, and K. S. Lee, "Post-earthquake damage evaluation for R/C buildings based on residual seismic capacity," in Proceedings of the 13th World Conference on Earthquake Engineering, vol. 1179, Vancouver, Canada, 2004. 
[12] J. W. Park, J. Y. Park, D. J. Kim, Y. H. Lee, and H. C. Kim, "Boundary nonlinear time history analysis of low-rise RC structure using the rubber 9 laminated lead damper," in Proceedings of the Computational Structural Engineering Institute of Korea, vol. 27, no. 1, pp. 193-195, Seoul, South Korea, 2014.

[13] Y. K. Wen, "Method for random vibration of hysteretic systems," Journal of the Engineering Mechanics Division, vol. 102, no. 2, pp. 249-263, 1976.

[14] JBDPA, Standard for Evaluation of Seismic Capacity of Existing Reinforced Concrete Buildings, Japan Building Disaster Prevention Association, Tokyo, Japan, 2003.

[15] Uniform Building Code (UBC), "Structural engineering design provision," in Proceedings of the International Conference of Building Officials, Whittier, Calif, USA, 1997.

[16] K. Takanashi, K. Udagawa, and H. Tanaka, "Pseudo-dynamic tests on a 2-storey steel frame by a computer-load test apparatus hybrid system," in Proceedings of the 7th World Conference on Earthquake Engineering, vol. 7, pp. 225-232, Istanbul, Turkey, 1980.

[17] Tokyo Soki Kenkyujo Company, Tokyo, Japan, http://www.tml .jp/e/.

[18] MTS, Pseudodynamic Testing For 793 Controllers, MTS Systems Corporation, Eden Prairie, Minn, USA, 1999.

[19] P. S. B. Shing, M. Nakashima, and O. S. Bursi, "Application of pseudodynamic test method to structural research," Earthquake Spectra, vol. 12, no. 1, pp. 29-56, 1996.

[20] H. M. Hilber, T. J. Hughes, and R. L. Taylor, "Improved numerical dissipation for time integration algorithms in structural dynamics," Earthquake Engineering \& Structural Dynamics, vol. 5, no. 3, pp. 283-292, 1977.

[21] R. Park, "Ductility evaluation from laboratory and analytical testing," in Proceedings of the Proceedings of 9th World Conference on Earthquake Engineering, vol. 8, pp. 605-616, Tokyo, Japan, 1988. 


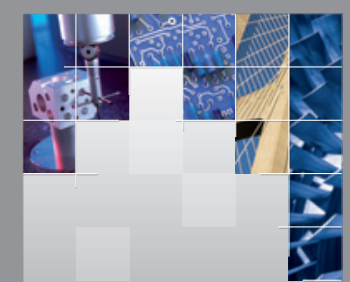

\section{Enfincering}
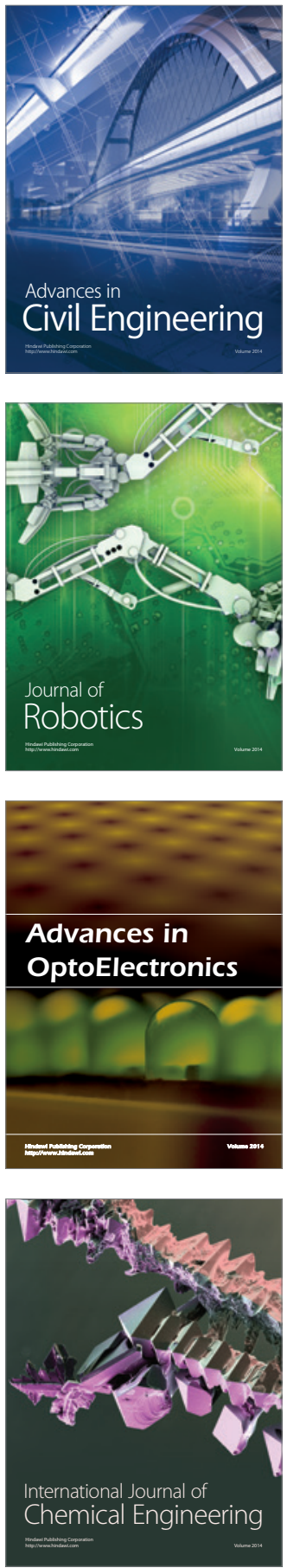

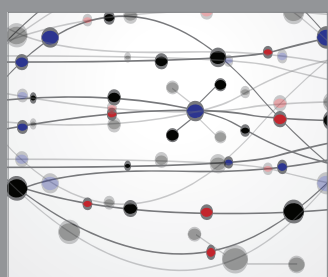

The Scientific World Journal

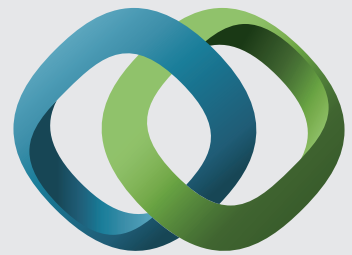

\section{Hindawi}

Submit your manuscripts at

http://www.hindawi.com
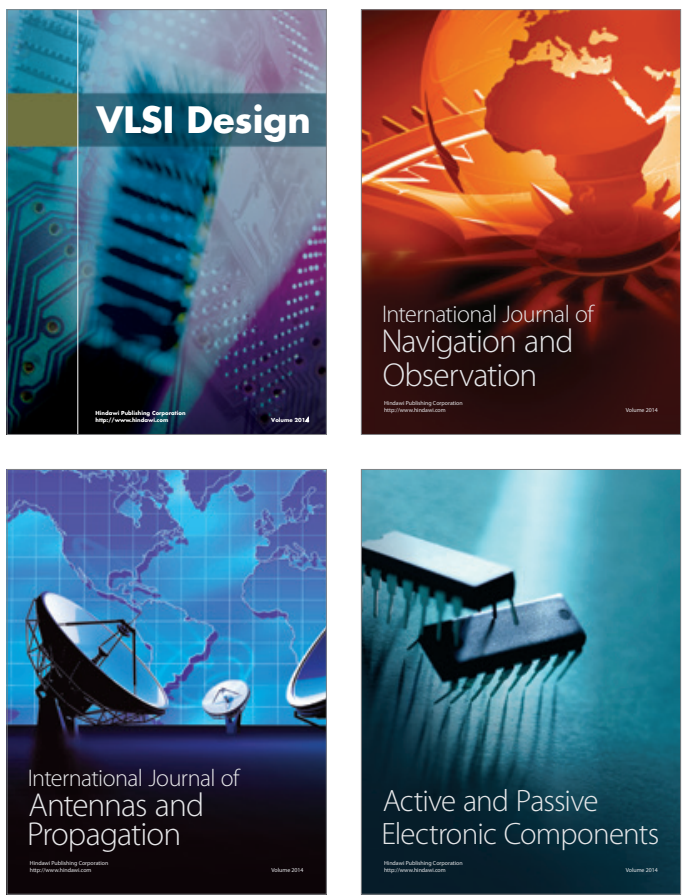
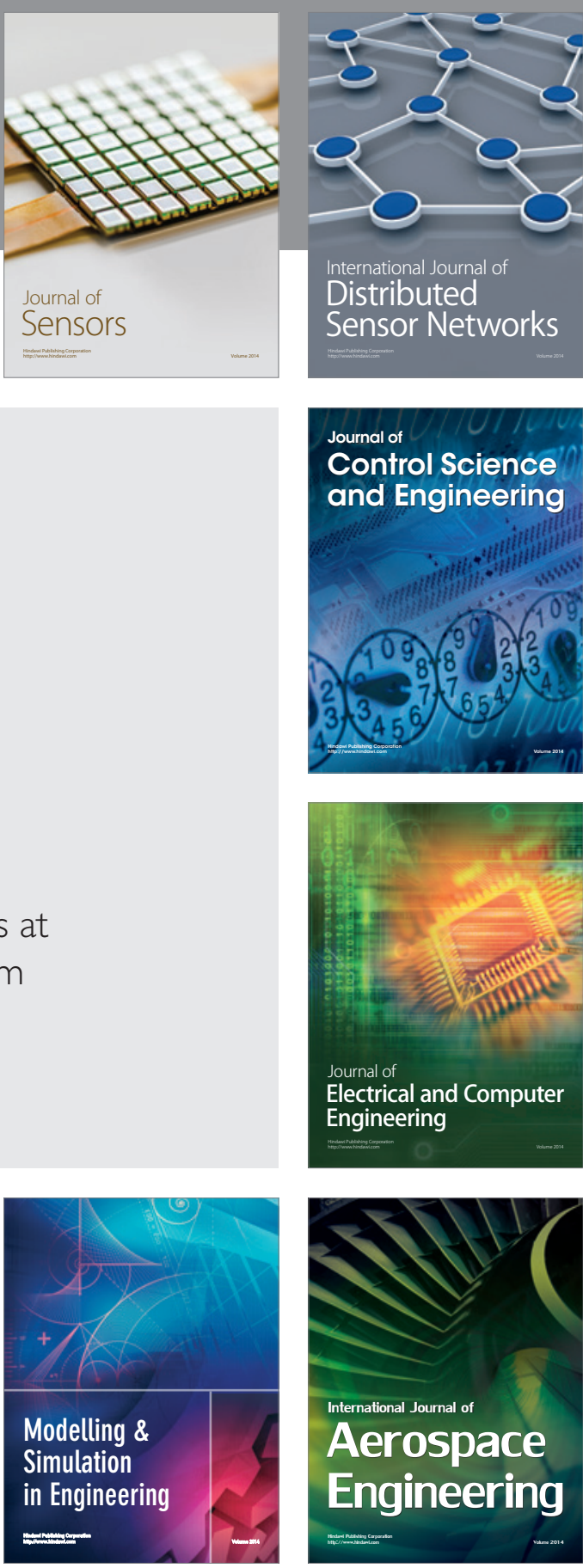

International Journal of

Distributed

Sensor Networks

Journal of

Control Science

and Engineering
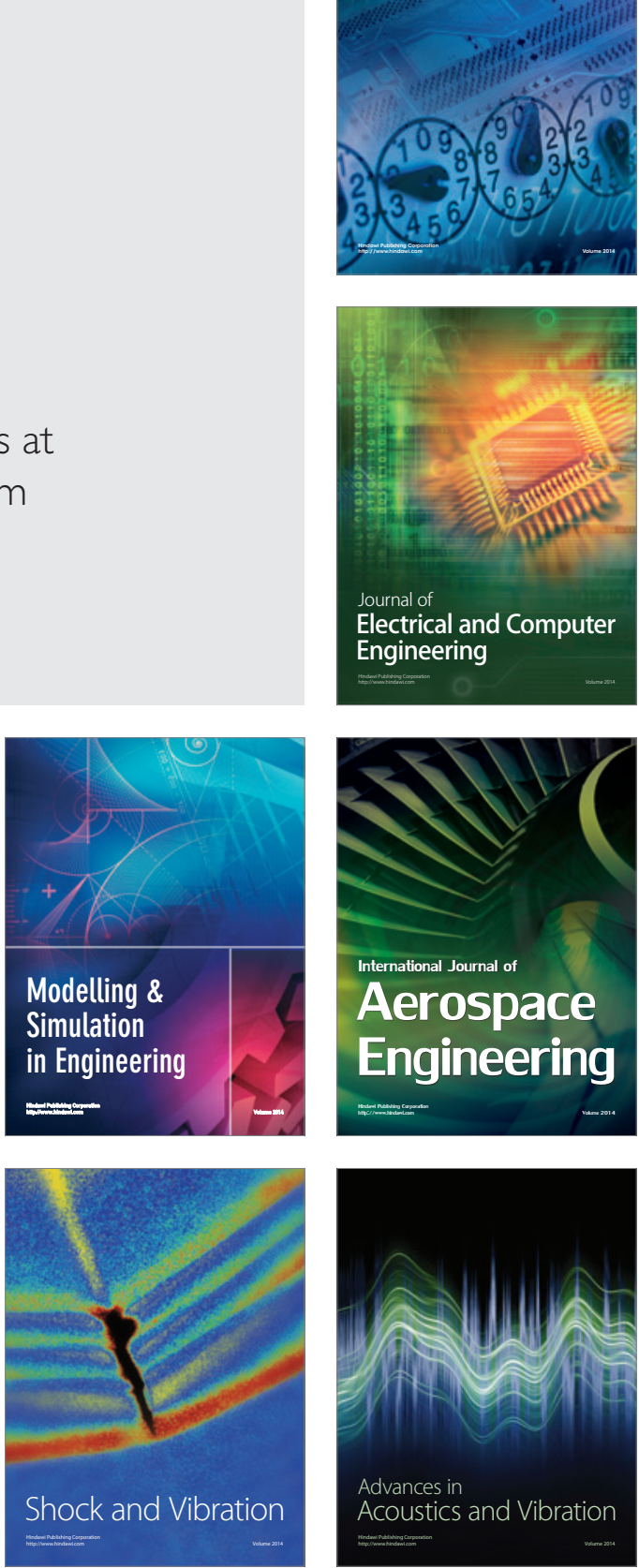